\title{
Multiscaling of shear zones and the evolution of the brittle-to-viscous transition in continental crust
}

\author{
C. E. Schrank, ${ }^{1,2}$ M. R. Handy, ${ }^{1}$ and F. Fusseis ${ }^{1,3}$
}

Received 2 November 2006; revised 10 September 2007; accepted 4 October 2007; published 31 January 2008.

[1] A new method is introduced for quantifying the scale and the intensity of strain localization from maps of natural shear zones. The method employs autocorrelation functions to determine local areal scales of geometric homogeneity. These homogenization scales are used to calculate scale-dependent localization fractions of deformed rock. The strain localization intensity is quantified from measurements of mean relative to maximum shear strain. This approach is used to analyze shear zones on different scales from an exposure (Cap de Creus, Spain) of the fossil brittle-to-viscous transition (BVT). Changes in the scaling characteristics of shear zones are interpreted to reflect a time sequence of localization during the evolution of the continental BVT. We show that shear zone scaling is related to inherited anisotropies (older schistosity, lithological layering, pegmatite bodies) and to the predominant mode of deformation (brittle, viscous). The length-towidth ratio of shear zones increases with their length up to the meter scale and decreases for larger length scales as they evolve from isolated shear fractures to interconnected mylonitic shear zones. Variations in strain localization intensity calculated along a single shear zone indicate that such shear zones weakened from their brittle tips to their mylonitic centers, thus driving their propagation and growth to larger scales. Our results imply that the BVT evolves by "network widening," a process whereby strain localizes on progressively larger scales until a dense network of weak, mylonitic layers tens to hundreds of meters wide and hundreds to thousands of meters long forms subparallel to the regional shearing plane.

Citation: Schrank, C. E., M. R. Handy, and F. Fusseis (2008), Multiscaling of shear zones and the evolution of the brittle-to-viscous transition in continental crust, J. Geophys. Res., 113, B01407, doi:10.1029/2006JB004833.

\section{Introduction}

[2] Rock deformation is observed to be homogeneous on some length scales and heterogeneous on others [e.g., Means, 1976; Poirier, 1980; Ramsay, 1980], but the systematic determination of these scales has remained an unresolved problem almost since the first detailed descriptions of rock deformation (e.g., Heim [1878] as cited by Milnes [1979]). This problem has been compounded by the methodological challenge of quantifying deformational heterogeneity on the broad range of scales over which such heterogeneity occurs in nature, from the width of mineral grains (microns-millimeters) to the length of plate boundary faults $\left(10^{2}-10^{4} \mathrm{~km}\right)$. Heterogeneous rock deformation on all these scales is manifested by discrete zones of displacement, termed shear zones, that are characterized by finite strain gradients both parallel and perpendicular to their

\footnotetext{
${ }^{1}$ Institut für Geologische Wissenschaften, Fachrichtung Geologie, Freie Universität Berlin, Berlin, Germany.

${ }^{2}$ Now at Department of Geology, University of Toronto, Toronto, Ontario, Canada.

${ }^{3}$ Now at School of Earth and Geographical Sciences, University of Western Australia, Perth, Western Australia, Australia.

Copyright 2008 by the American Geophysical Union. 0148-0227/08/2006JB004833\$09.00
}

length (Figure 1) (e.g., reviews by Ramsay [1980] and Carreras [2001]). At high strains, isolated shear zones link up to form a network of anastomosing shear zones that are oriented parallel to subparallel to the bulk shearing plane (Figures 1a-1c). The question arises of how such networks evolve in time and space, specifically whether the process of networking of shear zones involves changes in the characteristic length scales of shear zones and the mechanical properties of the sheared rocks (e.g., effective mechanical layer thickness, rheology).

[3] We use the term "scale" as a general expression for absolute spatial measures throughout this paper (in contrast to ratios common in maps). "Areal scale" refers to the size of an area, e.g., the total size of a shear zone in two dimensions. The length and width of a shear zone are measured along lines, respectively, subparallel and subperpendicular to the shearing plane (see definitions and measuring techniques in section 2.1).

[4] A network of shear zones narrows with increasing length when strain is progressively localized into fewer and narrower shear zones during their growth parallel to the shearing plane, while surrounding shear zones are deactivated. This evolution is termed "network narrowing" as opposed to "network widening" where initially isolated shear zones widen and coalesce, leading to the formation of a shear zone that is wider than the initial shear zone array 


\section{Time and strain}

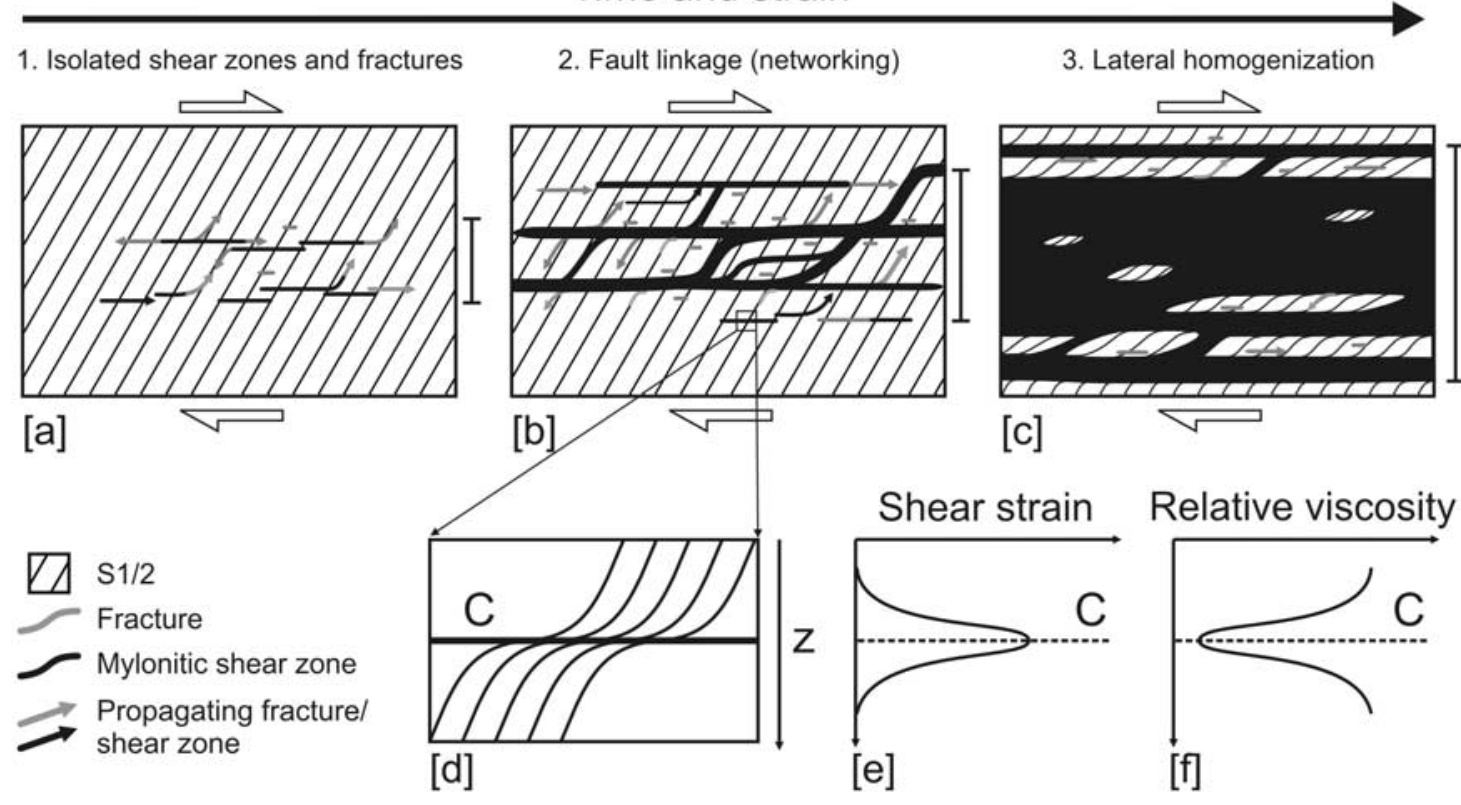

Figure 1. Stages in the development of a brittle-viscous shear zone network, modified from Fusseis et al. [2006] (with permission from Elsevier). (a) Nucleation. Shear zones initiate as shear fractures (thick grey lines) that propagate (arrowheads) parallel to the horizontal shear plane or obliquely along the existing S1/2 schistosity (thin black lines). The fractures become mylonitic shear zones (thick black lines) once a critical strain has accrued. The width of the fault array is denoted by the bar at the right of the diagram. (b) Fault linkage. Upon reaching a critical length, mylonitic shear zones link horizontally and obliquely along step over shear zones oriented parallel to S1/2. A network is established and the width of the shear zones within this network increases. (c) Lateral homogenization. Mylonitic deformation dominates as the network continues to widen. Lozenges of host rock rotate and are progressively overprinted (note the rotated, relict S1/2 foliation). (d) Close-up of a segment of mylonitic shear zone (shear plane labeled "C") showing drag folds of S1/2 that indicate heterogeneous shearing. (e) Schematic shear strain profile across shear zone in Figure 1d. (f) Effective viscosity profile for shear strain profile in Figure 1e [after Handy, 1994].

(Figures 1a-1c). Both network widening and network narrowing are processes that have been inferred for natural fault systems (network widening [Fusseis et al., 2006] and network narrowing [Walsh et al., 2001; Ben-Zion and Sammis, 2003, and references therein]) and observed in deformational experiments (network widening [Herwegh and Handy, 1996, 1998] and network narrowing [Tchalenko, 1970]). Yet the characteristic scales of deformational heterogeneity during these contrasting evolutions have never been quantified empirically for brittle-viscous shear zones.

[5] The need to quantify the scale of localized deformation arises from the desire to relate scaling characteristics to the micromechanisms of strain localization, as well as to rock physical attributes like anisotropy (a foliation, elongate minerals or mineral aggregates [Dutruge et al., 1995]) and rheology [Paterson, 2001]. Past scaling studies of deformation have invoked fractal statistics to define a range of geometric-scale invariance [Mandelbrot, 1982; Turcotte, 1990; Bonnet et al., 2001; Lei et al., 2003] for structures that may be diagnostic of the deformation mechanisms in the rocks analyzed. For example, Hippertt [1999] found that the spacing and aspect ratio of $\mathrm{S}$ and $\mathrm{C}$ shear surfaces in mylonite satisfy a fractal (i.e., power law) distribution over 6 orders of magnitude (micron to kilometer scales). Fractal dimensions have also been used to scale fault systems in the upper, brittle part of the continental crust [Cowie and Scholz, 1992; Bonnet et al., 2001, and references therein]. A drawback of this approach is that more than one rock physical attribute can influence the fractal dimension, especially when one considers a broad range of scales. This is especially true of rocks deformed at the transition from pressure-dependent frictional sliding to thermally activated, viscous creep (henceforth termed the brittle-viscous transition, or BVT), where several competing deformation mechanisms accommodate roughly equal amounts of strain [Handy et al., 2007]. Deviations from a fractal distribution may also reflect smaller-scale heterogeneities that induce strain incompatibilities and therefore govern rock mechanical behavior on larger scales [Ackermann et al., 2001]. Thus an analytical scaling method is needed that enables higher spatial resolution and that takes into account the changing physical and kinematic boundary conditions during progressive deformation.

[6] In this paper, we introduce a new method for quantifying both the scale and the intensity of strain localization from areal images of natural shear zones. The method employs autocorrelation functions (ACF) to determine local areal scales of geometric homogeneity, so-called elementary reference areas. These elementary reference areas allow us to calculate the fraction of rock that is deformed above a 
[a]

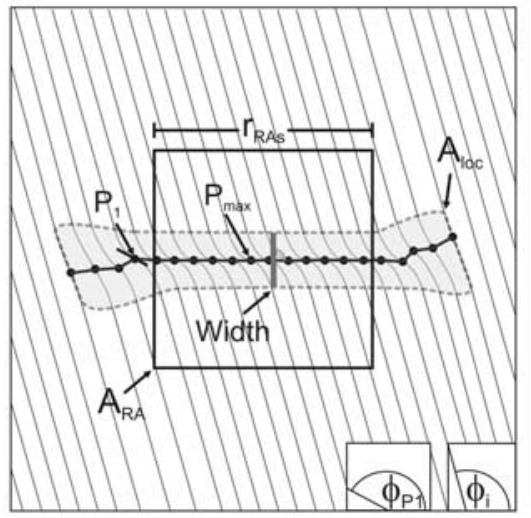

[b]

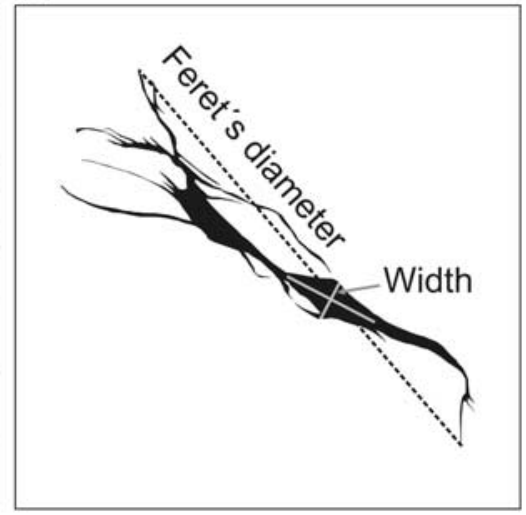

Figure 2. (a) Schematic view of an isolated shear zone showing main geometrical elements, including deformation of ideally passive markers (oblique solid lines). The grey area with the dashed outline marks the shear zone area, $A_{\text {loc }}$. Outside $A_{\text {loc }}$, markers have an initial orientation of angle $\phi_{\mathrm{i}}$ (bottom right corner) to the horizontal shearing plane. Inside $A_{l o c}$, markers are rotated (i.e., deformed), and their tangents have an orientation differing from $\phi_{\mathrm{i}}$, for example, at point $\mathrm{P} 1$. Compare the tangential angle $\phi_{\mathrm{P} 1}$ to $\phi_{\mathrm{i}}$ (bottom right). The shear zone center is defined at points where the angle $\phi_{\mathrm{P} 1}$ has a maximum deviation from $\phi_{\mathrm{i}}$ (black dots, example labeled $\left.\mathrm{P}_{\max }\right)$. The line linking these points defines the shear zone length. Shear zone width is measured normal to its length at the point of maximum displacement. $A_{R A}$ determined for this hypothetical example is represented as a black square with sides of length $r_{R A s}$. (b) Feret's diameter and shear zone width for large-scale example.

background level of strain for any given areal scale. In a parallel step, the intensity of strain localization is quantified as the normalized difference of maximum and mean shear strain for any regarded shear zone. We then apply this new method to shear zones from an exposure of the fossil brittleviscous transition at the Cap de Creus in NE Spain. It is shown that peaks in the scale and intensity of strain localization are related to a combination of existing anisotropies and the linkage of brittle-viscous shear zones. The scaling relationships change systematically with shear zone length, a feature which we term "multiscaling". We conclude with a conceptual model for the growth and coalescence of shear zones at the BVT involving strain localization on progressively larger scales.

\section{Methods}

\subsection{Parameterization of Shear Zones}

[7] We will assume for the sake of simplicity that deformation is isochoric and involves simple shear. Although natural deformation is usually three-dimensional, the deformation in many shear zones analyzed so far is nearly plane strain and highly noncoaxial [Ramsay, 1980; White et al., 1980]. This is also the case for the shear zones analyzed below (see section 3.1), so that all shear zones considered in this paper are viewed in or near the $\mathrm{XZ}$ plane of the bulk finite strain ellipsoid (X, shear direction; $\mathrm{Z}$, normal to the shear (XY) plane). Two-dimensional deformation is obviously easier to quantify with our method, but its principles can be extended to three dimensions. The shear zones analyzed below are mylonitic except at their brittle tips [Fusseis et al., 2006], such that deformation is regarded to have been nearly isochoric with only limited dilation.
[8] The shear zone area, $A_{10 c}$, is easily determined from a flat image (map or thin section photo) taken parallel to the $\mathrm{XZ}$ plane of the finite strain ellipse with $\mathrm{k}=1$ by measuring the area inside the borders of a shear zone. The borders are defined as points on a rock surface where the shear strain increases from zero or some average background value (outside the shear zone) to finite values greater than the outside value [Ramsay and Graham, 1970]. In other words, the border is formed by points at which $\partial \gamma /$ $\partial \mathrm{Z}=0$, where $\gamma$ is the shear strain. In foliated rocks like those at the Cap de Creus, it is convenient to define shear zone borders as lines on the outcrop surface where a passive or nearly passive marker (in this case, the trace of the existing schistosity) deviates from a background initial orientation, $\varphi_{\mathrm{i}}$ (Figures $2 \mathrm{a}, 3 \mathrm{c}$, and $3 \mathrm{~d}$ ). The shear zone border is therefore an isogon corresponding to zero deviation of the trace of S surfaces in the rock.

[9] The shear zone center is defined as a line connecting points of maximum deviation (i.e., maximum shear strain) of each (deformed) marker line from its initial orientation (Figure 2a). The shear zone length is the length of the line defining the shear zone center between the shear zone tips. The shear zone width is the distance between borders as measured normal to the shear zone center at the location of maximum displacement.

[10] These criteria could not be used for the largest-scale data due to the lack of appropriate markers on this scale (Figure 4). In order to establish a robust, reproducible measurement strategy and enable automated image analysis, the method was simplified. The shear zones were vectorized as polygons from the map of Fusseis et al. [2006]. Feret's diameter (i.e., the longest distance between any two points along the shear zone boundary, Figure $2 \mathrm{~b}$ ) was determined with the image analysis software ImageJ and taken as shear zone length. The width was measured at the thickest part of 

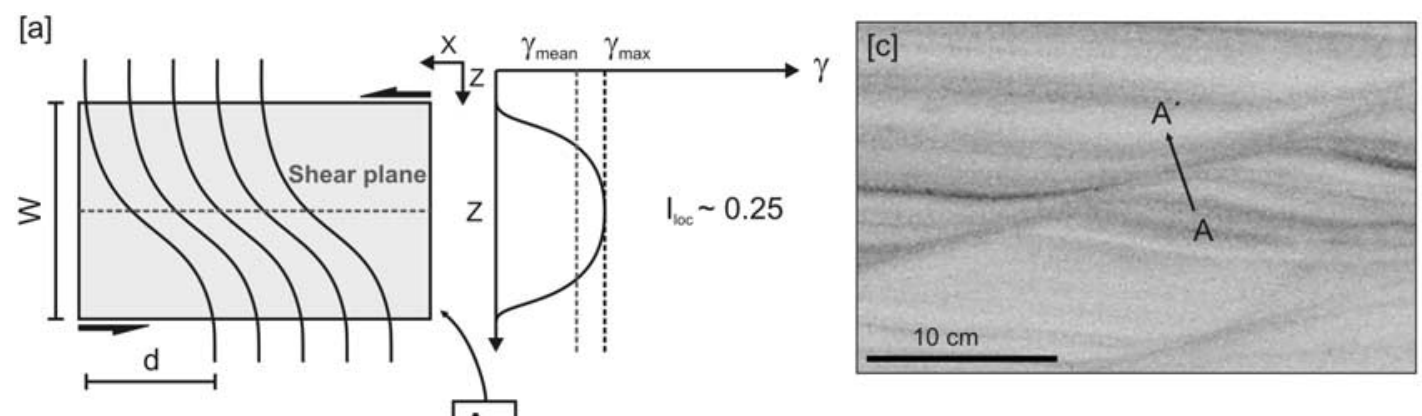

[b]
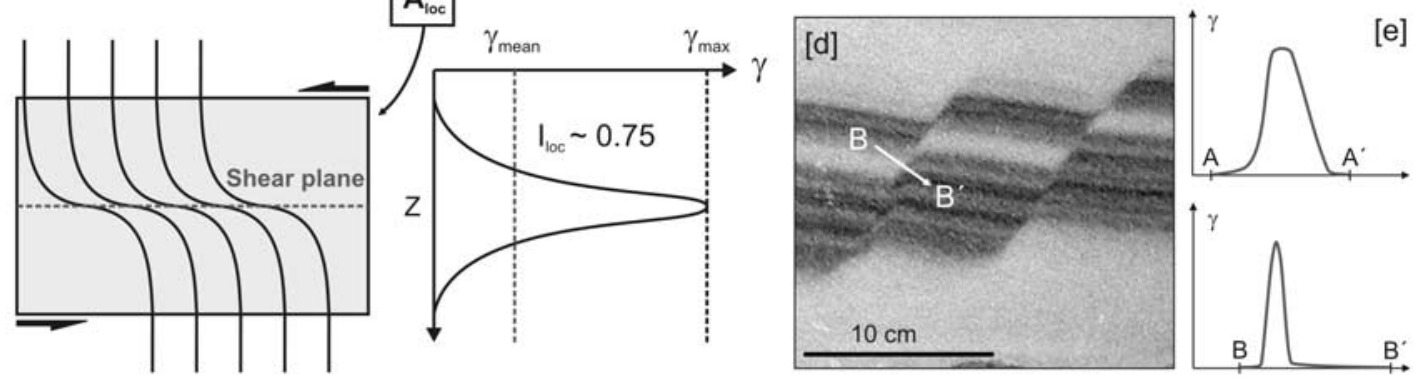

Figure 3. Idealized shear strain distributions for two end-member types of shear zones. Displaced markers and shear strain profiles are less heterogeneous (a) for the shear zone with low strain localization intensity than (b) for that with the high strain localization intensity. The shear zones have the same mean shear strain, $\gamma_{\text {mean }}$, and displacement, but the maximum shear strains, $\gamma_{\text {max }}$, differ. Shear zones in marble with (c) low and (d) high strain localization intensities have different shear strain profiles (see text).

the shear zone in a direction normal to the strike of the shear zone at that point (Figure $2 \mathrm{~b}$ ).

\subsection{Scaling Parameters}

[11] At least three parameters are needed to quantify strain localization on all scales: (1) the proportion of localized deformation per area of rock on a given scale; (2) the scale dependence of this proportion; and (3) the degree or intensity of the localization on a given scale. We refer to these three parameters, respectively, as the localization fraction $\left(\mathrm{Lf}_{\mathrm{RA}}\right)$, the scale dependence factor $\left(\mathrm{Lf}_{\mathrm{RA}}\right.$ as a function of shear zone length and width), and the localization intensity factor $\left(\mathrm{I}_{1 \mathrm{oc}}\right)$. Here, we introduce these parameters in turn before applying them to determine the scaling properties of some natural shear zones. We note that the approach adopted below can be modified and applied to other structures such as folds. However, this is beyond the scope of our paper.

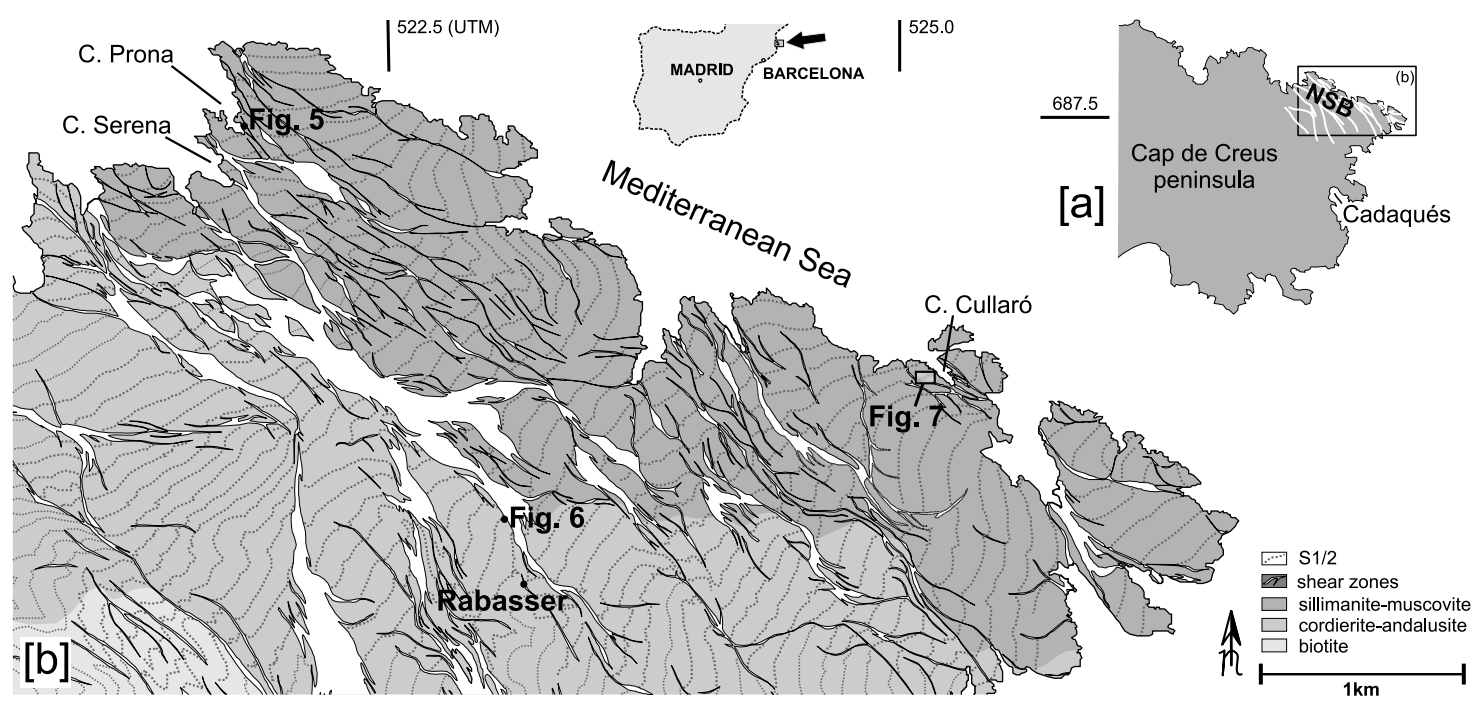

Figure 4. Maps of the Cap de Creus shear zones [after Carreras, 2001] (with permission from Elsevier). (a) Location of the Northern Shear Belt along the northern border of the Pyrenees. (b) Traces of the shear zones (white) and older S1/2 foliation (dotted lines) on the 100- to 1000-m scales. Notice locations of Figures 5, 6, and 7. Two small-scale data sets were collected at or near Rabasser (Figures 8, 9, 11, and 12); the shear bands referred to in the text as "Rabasser Metapelites" are shown in Figure 6 and labeled as such here. The "Rabasser Quartzites" are located at Rabasser. 


\subsection{Strain Localization Fraction, $\mathbf{L} \mathbf{f}_{\mathrm{RA}}$}

[12] Discretely structured matter is usually treated as a continuum by averaging its properties in space based on empirical considerations [e.g., Lai et al., 1996] and determining a homogenization scale or volume [Bonnet et al., 2001]. This is termed the "representative elementary volume" (REV) and is the smallest volume of the material containing all heterogeneities that appear statistically homogeneous at the scale of observation [Paterson, 2001]. The averaged mechanical properties of the REV are assumed to control material behavior at larger scales.

[13] By analogy with the REV for three-dimensional strain, we define a "representative reference area", $A_{R A}$, for two-dimensional deformation (Figure 2a) on a rock surface that contains undeformed host rock as well as all heterogeneities, such that together, they appear statistically homogeneous on the scale of observation. By calling this a representative reference area, we emphasize that the statistically homogeneous areas are used as a reference for defining the proportion (localization fraction) of sheared material at a given scale. As shown below in the next section, representative reference areas can be defined on several scales for the shear zones of the Cap de Creus.

[14] The localization fraction $\mathrm{Lf}_{\mathrm{RA}}$ is then defined as the ratio

$$
\mathrm{Lf}_{\mathrm{RA}}=\frac{\mathrm{A}_{\mathrm{loc}}}{\mathrm{A}_{\mathrm{RA}}},
$$

where $A_{R A}$ has been defined above (Figure 2a). $L f_{R A}$ is a dimensionless measure of how much area a particular shear zone covers compared to a statistically homogeneous area of host rock, i.e., the areal fraction of a shear zone in $A_{R A}$.

[15] Determining the reference area, $A_{R A}$, is crucial and therefore requires closer explanation. Consider a foliation map for rock containing a shear zone (Figure 2a). Three types of points on the map can be distinguished: (1) points within the shear zone, where marker lines deviate from their orientation outside of the shear zone; (2) the shear zone boundary; and (3) points outside the shear zone, where marker lines have an orientation or range of orientations that are regarded as initial or undeformed. These points are distinguished by comparing the orientation of tangents to the marker lines, $\varphi_{\mathrm{P}}$, all along these lines to a mean orientation interval of the initial, nonlocalized marker line, $\varphi_{\mathrm{i}}$, away from the shear zones (Figure 2a). If an orientation $\varphi_{\mathrm{P}}$ does not equal $\varphi_{\mathrm{i}}$, it is regarded as a localized orientation, $\varphi_{\text {loc }}$. At a point with orientation $\varphi_{\text {loc }}$, the marker line was rotated out of its initial orientation and hence has been sheared. The parameter $\varphi_{\mathrm{loc}}$ is an angle interval because markers in most shear zones are subject to heterogeneous simple shear [Ramsay and Graham, 1970].

[16] Obviously, the resolution of the shear zone boundaries is best for small variations in the marker orientation outside of the shear zone. For small variations, it is convenient to use the arithmetic mean and standard deviation of $\varphi_{\mathrm{i}}$ to define one initial (undeformed) orientation angle interval. In nature, however, $\varphi_{\mathrm{i}}$ often fluctuates across the outcrop surface due to folding or shearing prior to the activity of the shear zone in question. In this case, it is convenient to give $\varphi_{\mathrm{i}}$ as an angular interval corresponding to the upper and lower limits of all nonlocalized orientations. If $\varphi_{\mathrm{i}}$ is highly variable, then the image must be divided into subdomains, each with different local values of $\varphi_{\mathrm{i}}$.

[17] Once $\varphi_{\mathrm{i}}$ and $\varphi_{\text {loc }}$ are defined, the map is covered with a grid of square search windows of a given size. For each window, the mean foliation orientation is determined by ACF. Each window is assigned being an element of either $\varphi_{\mathrm{i}}$ (host rock) or $\varphi_{\text {loc }}$ (shear zone) based on its mean foliation orientation. Then the relative frequency of search windows with a localized orientation is calculated for this given grid (see Figure A1). This procedure is repeated for various search window sizes. $A_{R A}$ is defined as the area of the search window for the size of which $5 \%$ search windows with a localized mean orientation occur in the entire map. Hence if a search window with the area of $A_{R A}$ is placed on the map at a randomly selected location, there is a $95 \%$ probability that this search window will contain a homogeneous, nonlocalized foliation pattern. The choice of a $95 \%$ probability boundary to define $A_{R A}$ is arbitrary but yielded good results for the image data below and in the work of Schrank [2004]. It is also a common confidence boundary in statistics [e.g., Robinson and Bevington, 2003]. A higher probability boundary results in a larger $A_{\mathrm{RA}}$, possibly even greater than the area of the map regarded. This must be avoided because an $\mathrm{A}_{\mathrm{RA}}$ larger than the considered map would satisfy the homogeneity condition only if heterogeneities outside the map were distributed in the same way as in the map. This can be assumed, but may be unrealistic. A higher boundary would also yield smaller values for $\mathrm{Lf}_{\mathrm{RA}}$ which is mathematically inconvenient. If $A_{R A}$ cannot be determined for a given map, then the scale of observation is too small to satisfy the geometric homogeneity condition given above. A map of the same resolution but covering a larger area should be used. Note that $A_{R A}$ is an abstract area that satisfies the condition of statistical geometric homogeneity. Because of its derivation from a square search grid, we depict it as a square (Figure 2a) with sides of length $r_{\text {RAs }}$. $A_{R A}$ can also be represented as an isotropic area, i.e., a circle with diameter $r_{R A c}$. The procedure for deriving $A_{R A}$ from foliation maps with $\mathrm{ACF}$ is described in detail in Appendix A.

\subsection{Strain Localization Intensity Factor, $\mathbf{I}_{\text {loc }}$}

[18] The amount and distribution of strain can vary within a given shear zone area, $A_{\text {loc }}$ (Figure 3). In fact, shear strain usually varies both across and along shear zones [e.g., Ramsay and Graham, 1970], and this variation becomes more pronounced with increasing finite shear strain [Fusseis et al., 2006]. We define strain localization intensity to be the amplification of shear strain above an average value of shear strain in the same shear zone. Strain localization intensity is illustrated in Figure 3 by profiles of shear strain versus distance across the centers of two hypothetical shear zones. The shear zone with weakly localized (i.e., less heterogeneous) strain has a broad strain profile with a flat top (Figure 3a), whereas the shear zone with strongly localized strain has a profile with a high narrow peak above a wide, low base (Figure 3b). The latter profile indicates a greater strain localization intensity because higher shear strains are concentrated in a narrower zone, i.e., the shear strain is distributed more heterogeneously. Thus the shape of the shear strain profile is diagnostic of the variability and intensity of strain localization within a shear zone. 
[19] Natural shear zones often have irregular, asymmetric shear strain profiles [Ramsay and Graham, 1970, Figure 16; Lamouroux et al., 1994] that require complicated mathematical descriptions to quantify strain localization. To avoid these complications, we propose using a combination of the easily obtainable, geologically relevant parameters, $\gamma_{\text {mean }}$ and $\gamma_{\max }$, to describe the intensity of strain localization across shear zones. The parameter $\gamma_{\text {mean }}$ is the average shear strain of the shear zone, whereas $\gamma_{\max }$ is the maximum shear strain within the shear zone (Figure 3). The parameter $\gamma_{\max }$ can be calculated from the angles of deflected and undeflected markers with the relationship [Ramsay and Graham, 1970]

$$
\gamma_{\max }=\cot \alpha-\cot \alpha^{\prime}
$$

where $\alpha$ is the initial angle (i.e., undeformed orientation) of a marker line and $\alpha^{\prime}$ is the angle of maximum deflection within the shear zone, both measured with respect to the shear plane. The parameter $\gamma_{\text {mean }}$ can be obtained from the relation

$$
\gamma_{\text {mean }}=\frac{\mathrm{d}}{\mathrm{W}}
$$

where $\mathrm{d}$ is the total displacement along a shear zone of width $\mathrm{W}$ measured at the same location as the strain profile above. If strain markers are available, the displacement can be measured directly. Otherwise, it may be determined from the area under the strain profile curve according to the relation [Ramsay and Graham, 1970]

$$
\mathrm{d}=\int_{0}^{\mathrm{W}} \gamma \mathrm{dZ}
$$

For weakly localized profiles, $\gamma_{\text {mean }}$ is close to $\gamma_{\max }$. The difference of $\gamma_{\text {mean }}$ and $\gamma_{\max }$ is small (Figure 3a). For strongly localized strain profiles, $\gamma_{\text {mean }}$ is small due to the high proportion of small shear strain values. The difference of $\gamma_{\text {mean }}$ and $\gamma_{\max }$ is large (Figure 3b). The difference of $\gamma_{\text {mean }}$ and $\gamma_{\max }$ normalized to $\gamma_{\max }$ is used as a measure of strain localization intensity, $\mathrm{I}_{\mathrm{loc}}$,

$$
\mathrm{I}_{\mathrm{loc}}=\frac{\left(\gamma_{\max }-\gamma_{\mathrm{mean}}\right)}{\gamma_{\max }}=1-\frac{\gamma_{\operatorname{mean}}}{\gamma_{\max }} .
$$

For shear zones with weakly localized strain profiles, i.e., low strain localization intensity, the ratio of $\gamma_{\text {mean }}$ to $\gamma_{\max }$ is large and $\mathrm{I}_{\mathrm{loc}}$ tends to zero. Shear zones with strongly localized profiles and high strain localization intensity have small ratios of $\gamma_{\text {mean }}$ to $\gamma_{\max }$, so $\mathrm{I}_{\mathrm{loc}}$ tends to one. Natural examples of shear zones with low and high strain intensities are shown in Figures 3c and 3d.

\section{Application of Scaling Methods to the Shear Zones at the Cap de Creus, NE Spain}

\subsection{Geology of the Shear Zones}

[20] Shear zones of the Northern Shear Belt at the Cap de Creus peninsula of NE Spain (Figure 4) are ideally suited for testing the scaling methods developed above. This shear belt is a deeply eroded part of a fossil, intraplate fault that accommodated dextral motion in Early Permian time [Carreras, 2001]. The shear belt evolved during a continuous deformational event that initiated at upper amphibolite-facies conditions [Carreras and Druguet, 1994; Druguet et al., 1997; Alfonso et al., 2003; Bons et al., 2004] and ended under retrograde greenschist-facies conditions at $\sim 350^{\circ} \mathrm{C}$ and $0.3 \mathrm{GPa}$ [Druguet, 2001]. The greenschistfacies shear zones analyzed below formed in metasediments that are lithologically heterogeneous, with preexisting, alternating micaceous and quartz-rich sequences up to tens of meters thick. These sequences represent both sedimentary layering (centimeter to $10-\mathrm{m}$ scale, S0) and a dominant transposed, composite foliation (millimeter to centimeter scale, S1/2) [Carreras, 2001]. These features are shown below to affect the scaling of the shear zones. S1/2 is orientated regionally at high angles $\left(70^{\circ}-90^{\circ}\right)$ to the mylonitic shearing plane of the greenschist-facies shear zones that contain a mylonitic foliation, S3 (Figure 4b) [Carreras, 2001; Fusseis et al., 2006]. Adjacent to these shear zones, $\mathrm{S} 1 / 2$ is deflected toward the shearing plane. S1/2 therefore serves as an excellent marker for the quantification of displacement and strain [Fusseis et al., 2006]. Pegmatites and granitoids concordant to $\mathrm{S} 1 / 2$ are cut by and therefore predate the greenschist-facies shear zones. These magmatic rocks are inferred to have intruded syntectonically at the peak of upper amphibolite-facies metamorphism [Carreras and Druguet, 1994; Druguet and Hutton, 1998; Alfonso et al., 2003; Bons et al., 2004].

[21] To interpret the scaling characteristics of the shear zones, it is crucial to understand their evolution as inferred from a spatial sequence of strain and structures observed across the Cap de Creus peninsula. We follow the model of Fusseis et al. [2006] which is briefly summarized here: The shear zones nucleated as shear fractures parallel to the later mylonitic shearing plane (Figure 1a). These fractures are filled with the same retrograde, greenschist-facies minerals that make up the S3 mylonitic foliation, indicating that fracturing clearly postdated amphibolite-facies conditions and was temporally related to the development of the mylonitic shear zones [Fusseis and Handy, 2006; Fusseis, 2006, chapter 4]. Individual fractures never exceed $3 \mathrm{~m}$ in length, although multiple strands of composite brittle faults occasionally reach maximum lengths of $10 \mathrm{~m}$. Most fractures are flanked on either side by drag folds with rounded hinges that apparently formed by ductile, mylonitic flow. This indicates coeval activity of brittle and viscous deformation mechanisms. Increasing displacement on the fractures was associated with the development of a mylonitic foliation along their central segments establishing a viscously deforming shear zone center, while their tips continued to propagate (Figures 1a and 1b) [Fusseis, 2006, chapter 4]. This is interpreted as the onset of a straindependent BVT. In this way, the shear zones lengthened, widened, and eventually interconnected to form a network of mylonitic shear zones (Figure 1b). The linkage of the shear zones therefore represents a strain-dependent switch from dominantly brittle to dominantly viscous deformation on the scale of the shear zone network. The network comprises main shear zones oriented parallel to the bulk shearing plane linked by step over shear zones that propa- 

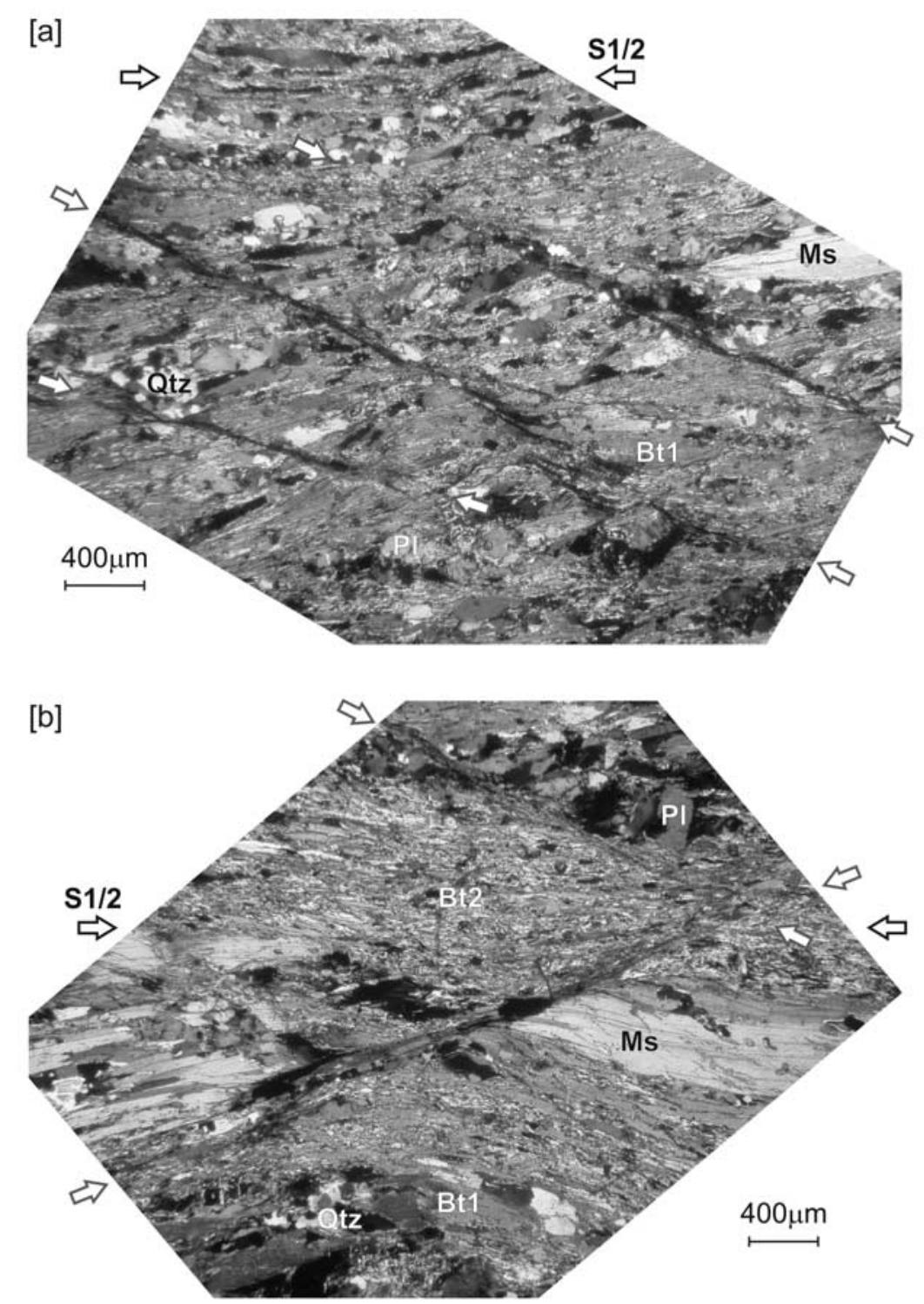

Figure 5. Shear zones on the millimeter scale. The images were rotated so that $\mathrm{S} 1 / 2$ (horizontal arrows) is horizontal and then cropped to save space. Oblique arrows mark shear bands. (a) S1/2 is defined by biotite-rich domains (Bt1) alternating with microlithons of elongate quartz (Qtz) and minor plagioclase (Plag) that are locally warped around muscovite porphyroclasts (Ms). In both S1/2 and the shear bands, Bt1 reacted syntectonically to form fine-grained aggregates of secondary Bt2, Ms, chlorite (Chl), and ilmenite (Ilm). (b) Boudinaged Ms porphyroclast. Note fine-grained syntectonic aggregates of Bt2, Ms, $\mathrm{Chl}$, and Ilm that define the mylonitic foliation in the retrograde, greenschist-facies shear zones. See text for explanation. Both pictures are taken with crossed polarizers of thin sections oriented parallel to the XZ plane (sample CC08, location in Figure 4b).

gated parallel or at low angles to S1/2 (Figures $1 \mathrm{a}-1 \mathrm{c}$ ), but at high angles to the main shear zones. The network encloses lozenges of less deformed country rock that were progressively overprinted as the shear zones broadened and the step over shear zones rotated (Figures $1 \mathrm{~b}$ and 1c). Deformation therefore homogenized on a larger scale than at the onset of strain localization (network widening, Figures 1a-1c).

[22] Most of the large-scale shear zones in Figure 4b dip moderately to steeply toward the NE (mean azimuth orientation 028/50 NE) with their mean stretching lineation (azimuth orientation 30/332) gently plunging to the NW [Carreras, 2001]. Slip line analysis of the mylonitic foliations and stretching lineations in the shear zone network reveals that deformation was highly noncoaxial on the scale of the network [Fusseis et al., 2006].

\subsection{Determination of $\mathbf{L} \mathbf{f}_{\mathbf{R A}}$ for Different Scales}

[23] $\mathrm{Lf}_{\mathrm{RA}}$ was determined for shear zones mapped from photographs of thin sections and outcrops, aerial photographs, and a structural map of the Cap de Creus peninsula (Figures 4-7). $\mathrm{Lf}_{\mathrm{RA}}$ was then plotted against the $\log$ of shear zone length (Figure 8) and shear zone width (Figure 9). The 


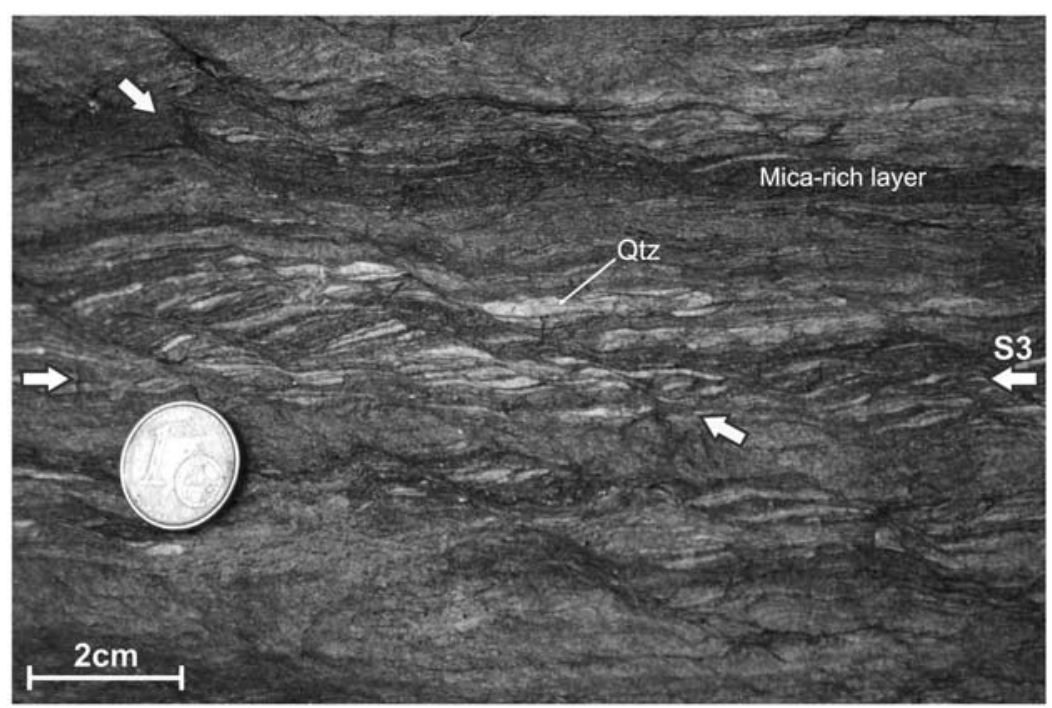

Figure 6. Shear zones on the centimeter to decimeter scales. Outcrop location marked in Figure 4b, data set labeled "Rabasser Metapelites" in Figures 8, 9, and 12. These shear bands are located at the margin of a larger shear zone. Its mylonitic foliation, S3, is oriented parallel to the shear plane and its shear bands slant to the right (grey oblique arrows). Note the asymmetric boudinage of quartz ribbons (Qtz) and the splayed terminations of shear bands in mica-rich layers.

names and localities of the samples analyzed below are shown in Figure $4 \mathrm{~b}$. These samples all come from shear zones with well-defined boundaries, which is essential for our analysis. The millimeter- to decimeter-scale samples are from sections normal to the shear plane and parallel to the shear direction. The meter- to kilometer-scale data deviate somewhat from this ideal orientation. The consequences of this bias are discussed below.

[24] The data clusters in Figure 8 can be fit to a power law function:

$$
\mathrm{Lf}_{\mathrm{RA}}=\mathrm{C}_{\mathrm{L}} \mathrm{L}^{\mathrm{D}_{\mathrm{L}}}
$$

where $C_{L}$ and $D_{L}$ are power law parameters for each scale range and $\mathrm{L}$ is the shear zone length. A similar, though poorer fit with the same parameters was obtained for a plot of $\mathrm{Lf}_{\mathrm{RA}}$ versus shear zone width, W (Figure 9). The geometric and mechanical significance of these parameters is discussed below.

\subsubsection{Uncertainties}

[25] The analysis of two-dimensional images/maps has some basic problems: The slicing effect of the erosional surface on the apparent shape of the shear zones leads to a systematic underestimate of the actual widths and areas of the kilometer-scale shear zones. Moreover, these shear zones dip between $35^{\circ}$ and $85^{\circ}$, with stretching lineations

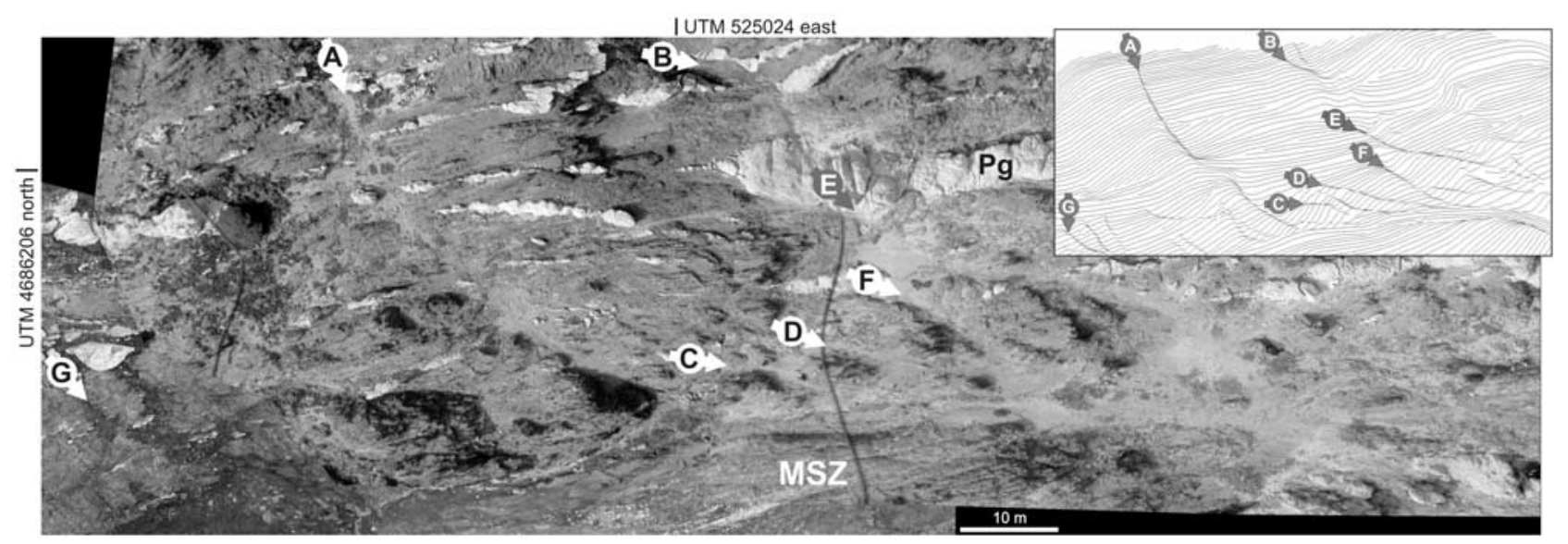

Figure 7. Aerial photograph mosaic showing shear zones on the scale of tens of meters. Area (Cala Cullaró) corresponds to the box in Figure 4b. The labels with letters denote the location of shear zones in the corresponding foliation map in the inset (top right). The foliation map was used for the ACF calculations. Note how shear zones terminate at large white leucocratic pegmatite bodies (Pg, examples B and C). "MSZ" indicates the main shear zone at the bottom. The curved, dark, subvertical line ending to the right of the label "MSZ" is a shadow cast by the kite used to take the photos. 




Figure 8. Localization fraction $\left(\mathrm{Lf}_{\mathrm{RA}}\right)$ versus length of the shear zones in the Cap de Creus area. Description of measurement technique is given in Appendix A. Box above the plot shows the range of widths of existing (inherited) anisotropies as measured in thin section and outcrop. The bar for the largest-scale data labeled "metamorphic zonation" is estimated from the maps of Carreras [2001] and Druguet [2001], as depicted in Figure 4. Black squares with dashed black lines mark the size of $\mathrm{r}_{\mathrm{RAs}}$, the length of a side of the square with the area $A_{R A}$. Grey circles with solid grey lines depict the size of $r_{R A c}$, the diameter of the circle with area $A_{R A}$.

parallel to the shear direction plunging approximately $30^{\circ}$ to the NW on average [Carreras, 2001]. Hence the trace of the shear zone boundaries on the subhorizontal outcrop surface makes some of the largest, kilometer-scale shear zones appear broader with respect to their length than for vertically dipping shear zones with ideally horizontal stretching lineations. However, the decrease in the length-to-width ratio of $100-\mathrm{m}$ - to kilometer-scale shear zones cannot be explained by the sectioning effect alone. The aspect ratio decreases by at least a factor of 5 from $100 \mathrm{~m}$ to kilometer scales, whereas the sectioning effect underestimates the aspect ratio by a factor of 1.5 (based on the mean orientations of the large-scale shear zones and their stretching lineation from Carreras [2001]). This orientational bias can be ruled out for the small-scale data because appropriate outcrops were selected.
[26] Truncation effects associated with the resolution limits of maps potentially lead to an underestimation of the frequency of small structures [Bonnet et al., 2001], resulting in a slight, but in this case, minor underestimation of $A_{R A}$. Shear zones on the kilometer scale are often longer than the largest areas imaged. Indeed, the largest shear zones at the scale of the Pyrenean mountain belt cannot be analyzed due to our basic inability to see them in their entirety at the surface. This selectivity or "censoring effect" [Bonnet et al., 2001] leads to a bias toward the analysis of small-scale structures. Both the truncation and censoring effects are unavoidable in any imaging method [Bonnet et al., 2001], but their effects on the data below are probably negligible.

[27] Earlier studies demonstrated that shear zone terminations propagate out of the XZ plane of the strain ellipsoid 


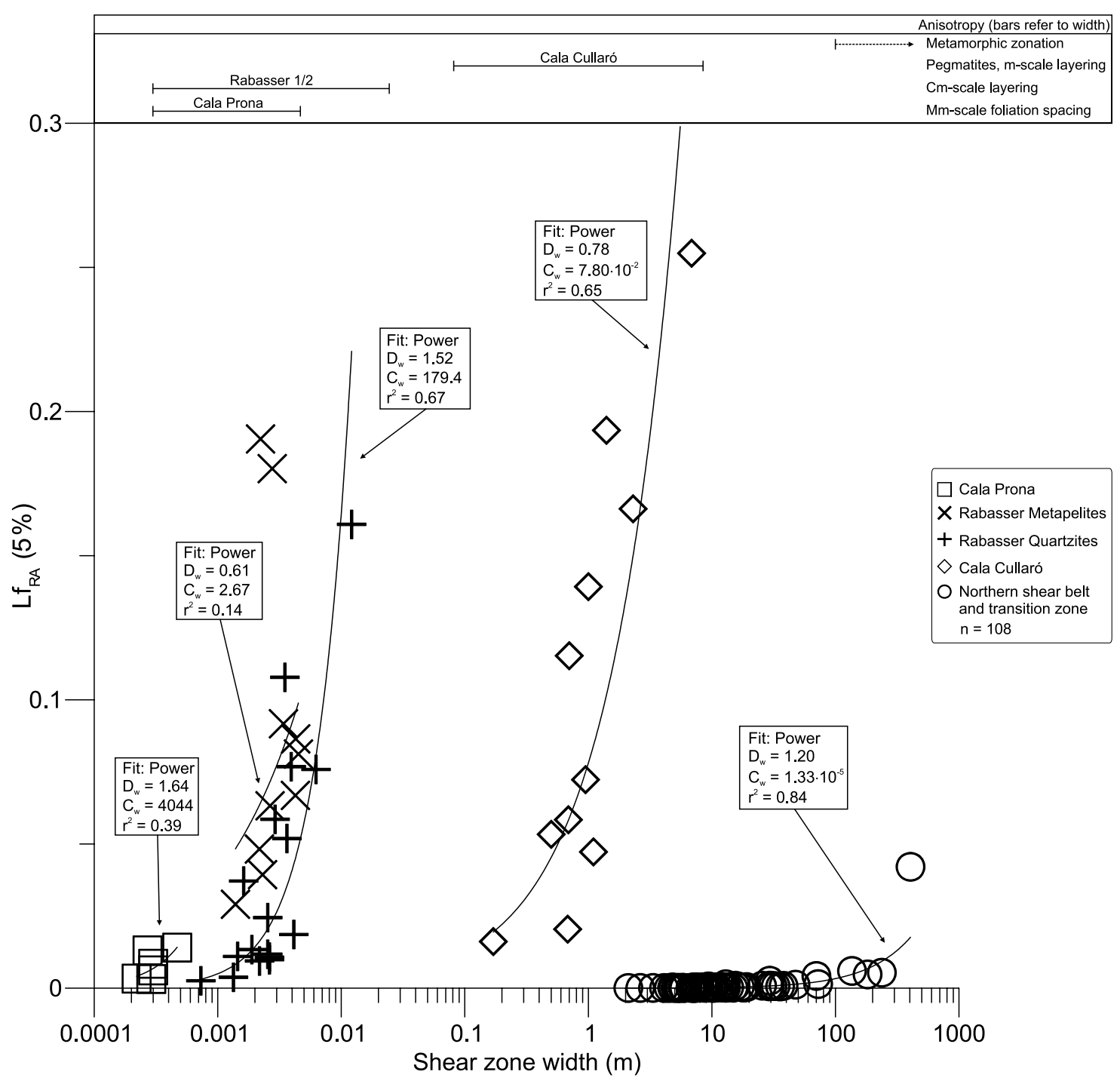

Figure 9. Localization fraction $\left(\mathrm{Lf}_{\mathrm{RA}}\right)$ versus width of the shear zones in the Cap de Creus area. Box above the plot shows the range of widths of existing (inherited) anisotropies as measured in thin section and outcrop. The bar for the largest-scale data labeled "metamorphic zonation" is estimated from maps of Carreras [2001] and Druguet [2001], as depicted in Figure 4.

and therefore do not reflect simple shear [Coward, 1976; Ramsay, 1980; Simpson, 1983]. Thus a flattening component of strain occurs that we cannot always see, especially in 100-m- to kilometer-scale shear zones. However, the importance of this pure shear component at the shear zone tips is minor and decreases with increasing shear zone length because the tip volumes become small relative to the entire shear zone volume. Certainly, the slip line analysis of mylonitic foliations and stretching lineations from Fusseis et al. [2006] reveals that the bulk deformation in the Northern Shear Belt was predominantly simple shear, with only a minor component of coaxial strain.

[28] Fortunately, we can rule out sampling bias [e.g., Nicol et al., 1996] as an explanation for the scale-dependent effects on rock structure, because the excellent outcrop exposure at Cap de Creus precludes any observational gaps. We actually see localization structures and existing anisotropies from the grain scale to the scale of the entire Northern Shear Belt.

\subsubsection{Results}

[29] Figures 8 and 9 reveal some interesting trends (see also Table 1). First, there is a striking gap in the scale of localization over lengths of several decimeter to meters, and widths of centimeter to decimeter. This contrasts with overlaps of both shear zone length and width at other scales. Second, the widths of preexisting anisotropies (foliation spacing, lithological layer thickness) and peaks in the $\mathrm{Lf}_{\mathrm{RA}}$ length plots coincide with the characteristic widths of $A_{R A}$. Third, the length-scaling exponent, $\mathrm{D}_{\mathrm{L}}$, is nearly 1 for the smallest shear zones on the millimeter to centimeter scales and increases with shear zone length attaining a value of 1.71 for $100-\mathrm{m}$ - to kilometer-long shear zones. The widthscaling exponent, $\mathrm{D}_{\mathrm{w}}$, also varies with shear zone width but less systematically. The correlation coefficients for the power law fits are poor due to increasing importance of measurement errors (the width determination error is larger compared to shear zone width than to shear zone length) and other reasons (above). In the following, we offer 
Table 1. Table of Scaling Factors for Shear Zones on Different Scales in the Cap de Creus Area

\begin{tabular}{|c|c|c|c|c|c|c|c|c|c|}
\hline Locality & $\begin{array}{c}\mathrm{Lf}_{\mathrm{RA}} \\
\text { Maximum, } \\
\%\end{array}$ & $\mathrm{D}_{\mathrm{L}}$ & $\mathrm{C}_{\mathrm{L}}$ & Dw & $\mathrm{Cw}$ & $\mathrm{r}_{\mathrm{RAc}}$ & $\mathrm{r}_{\mathrm{RAs}}$ & Type of Anisotropy & $\begin{array}{l}\text { Width Interval of } \\
\text { Anisotropy }\end{array}$ \\
\hline Cala Prona (thin sections) & 1.4 & 1.03 & 1.5 & 1.64 & $4.04 \times 10^{3}$ & $8.5 \mathrm{~mm}$ & $1.5 \mathrm{~cm}$ & $\begin{array}{l}\text { spacing of cleavage domains } \\
\text { Ms clasts }\end{array}$ & $\begin{array}{c}{[1 ; 5] \mathrm{mm}} \\
{[0.5 ; 2] \mathrm{mm}}\end{array}$ \\
\hline Rabasser Metapelites & 19.1 & 1.13 & 3.32 & 0.61 & 2.67 & $1.8 \mathrm{~cm}$ & $3.2 \mathrm{~cm}$ & spacing of cleavage domains & {$[0.04 ; 2.4] \mathrm{cm}$} \\
\hline Rabasser Quartzites & 16.1 & 1.45 & 2.12 & 1.52 & 179.4 & $4.0 \mathrm{~cm}$ & $7.0 \mathrm{~cm}$ & spacing of cleavage domains & {$[0.03 ; 2.2] \mathrm{cm}$} \\
\hline Cala Cullaro & 25.5 & 1.58 & $4.02 \times 10^{-4}$ & 0.78 & $7.80 \times 10^{-2}$ & $13.5 \mathrm{~m}$ & $23.9 \mathrm{~m}$ & $\begin{array}{l}\text { pegmatite thickness } \\
\text { sedimentary layering }\end{array}$ & $\begin{array}{l}{[0.08 ; 8.4] \mathrm{m}} \\
{[0.10 ; \sim 3] \mathrm{m}}\end{array}$ \\
\hline Northern Shear Belt & 4.2 & 1.71 & $1.14 \times 10^{-8}$ & 1.20 & $1.33 \times 10^{-5}$ & $2369 \mathrm{~m}$ & $4199 \mathrm{~m}$ & metamorphic zonation? & {$[\sim 100 ; \sim 7000] \mathrm{m}$} \\
\hline
\end{tabular}

possible explanations for these trends, especially the effects of existing structure and deformation mechanisms that operate on different scales.

\section{Interpretation and Discussion}

[30] Several factors affect the geometry of shear zones, foremost the lithology and inherited structure (i.e., the structure existing prior to the formation of the shear zones [Carreras, 2001]), and the deformation mechanisms and rheology of the rocks during shearing (Figures 4-7 and Table 1). In the following, we focus on the effects of lithology, deformation mechanisms, and rheology. The influence of inherited structure has been investigated in detail elsewhere [Carreras, 2001; Fusseis et al., 2006].

\subsection{Role of Preexisting Anisotropies}

[31] The ranges of individual $\mathrm{Lf}_{\mathrm{RA}}$ width distributions and also of some of the $\mathrm{Lf}_{\mathrm{RA}}$ length distributions of the shear zones correlate quite well with the ranges of widths (i.e., the thickness) of preexisting anisotropies, as plotted on logarithmic scales at the tops of Figures 8 and 9. Note that the mechanical anisotropies identified in our field examples are all parallel to $\mathrm{S} 1 / 2$. This close relationship between shear zone width and the width of inherited structures is readily observed in the rocks themselves: On the smallest (millimeter) scale, the shear bands emanate from micaceous domains in S1/2 and from the edges of muscovite clasts (Figure 5a), whereas on the centimeter scale (Figure 6) the shear bands are developed in alternating layers of micaceous schist ( 0.03 to $2.2 \mathrm{~cm}$ wide) and boudinaged quartz aggregates. The meter- to decameter-long shear zones (Figure 7) also splay from such layers, as well as from the margins of decimeter- to 10 -m-wide pegmatite bodies [Druguet et al., 1997]. No inherited anisotropies are evident on the scale of the kilometer-long shear zones. However, it is notable that these large shear zones are restricted to the part of the Northern Shear Belt with the highest metamorphic grades (cordierite-andalusite/sillimanite-muscovite [Druguet, 2001]) and are oriented subparallel to the metamorphic isograds (Figure 4).

[32] These relationships suggest that the mechanical and geometric properties of preexisting anisotropies controlled localization on the same or similar scales. On the millimeter scale, nucleation of shear bands along muscovite clasts and micaceous layers may reflect stress concentrations that arise from strain incompatibilities between the micas and the adjacent quartz-rich layers undergoing predominantly dislocation creep. Such stress concentrations can enhance creep locally [Lloyd and Knipe, 1992; Mainprice et al., 2004] or induce shear fracturing [Gottschalk et al., 1990; Shea and Kronenberg, 1993; Holyoke and Tullis, 2006], especially in the presence of a fluid at hydrostatic to nearlithostatic pressure [Bauer et al., 2000a, 2000b]. Indeed, Shea and Kronenberg [1993] found that shear fractures nucleated in microlithons in experimentally deformed micaschist. Shea and Kronenberg emphasized the importance of the initial spacing and concentration of micas and nonmicaceous aggregates in nucleating such fractures. The shear bands in Figure 5 are interpreted to have formed as transgranular shear fractures during the early stages of strain localization, then to have undergone a combination of diffusion-accommodated grain boundary sliding in quartz and plagioclase, and basal [001] glide in newly crystallized micas [Fusseis, 2006, chapter 4].

[33] Lithological control of localization is also evident at the margins of centimeter- and decimeter-scale shear zones, where quartz-rich layers subparallel to $\mathrm{S} 1 / 2$ are smoothly deflected across the shear zone (i.e., show moderate values of $\mathrm{I}_{\mathrm{loc}}$ ), whereas micaceous layers are bent sharply (highly localized strain, high $\mathrm{I}_{\text {loc }}$ values) and completely thinned out in the mylonitic centers of the shear zones. This corroborates many experimental and theoretical studies showing that strain localization is governed by the mechanical properties (e.g., viscosity contrast, number and thickness of layers [Ramberg, 1955; Biot, 1964]) as well as the orientation of existing anisotropies (e.g., schistosity, lithological layering) with respect to the shearing plane [Cobbold et al., 1971; Cosgrove, 1989].

[34] The general coincidence of kilometer-scale shear zones with the orientation and location of regional metamorphic zones (Figures 4 and 8) may be fortuitous but may also reflect the inherited effects of earlier metamorphism and magmatism on rock rheology during shearing. Specifically, prograde metamorphism culminating in the intrusion of pegmatitic dikes prior to the formation of the greenschistfacies shear zones [e.g., Druguet and Hutton, 1998; Alfonso et al., 2003] may have lead to spatial variations in the rocks' volatile content, especially in their water concentration. Rock deformation experiments have documented the weakening effect of volatiles, especially of dissociated water, on silicate mineral aggregates undergoing intergranular and intragranular creep (e.g., review by Carter and Tsenn [1987]). Given the ubiquity of microstructures that are diagnostic of dislocation creep in the largest shear zones at Cap de Creus [Fusseis et al., 2006], it is tempting to speculate that these shear zones nucleated and grew prefer- 


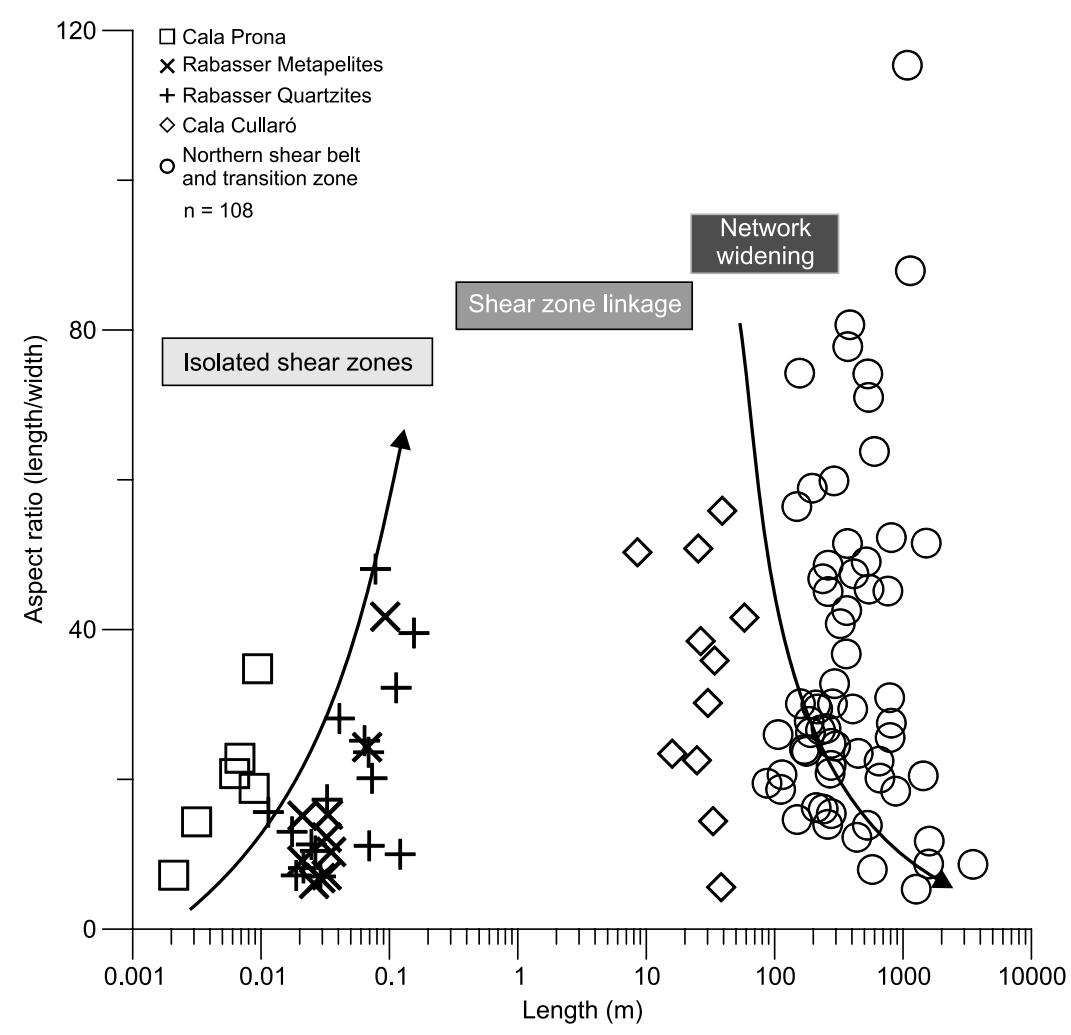

Figure 10. Plot of aspect ratio of shear zones versus shear zone length.

entially in areas that had previously been enriched in fluids during prograde devolitalization reactions and magmatism.

[35] Interestingly, the widths, $r_{R A s}$ and $r_{R A c}$, of the local homogenization scale, $A_{R A}$, coincide with the maximum thickness of the existing anisotropies with an accuracy better than an order of magnitude (Table 1 and Figure 8). The parameters $r_{R A s}$ and $r_{R A c}$ also coincide with peaks in the $\mathrm{Lf}_{\mathrm{RA}}$ length plot, but less well. Since $\mathrm{A}_{\mathrm{RA}}$ is defined arbitrarily, this relation might be an artifact of our method and requires further testing with other data. Nevertheless, given the observation that the shear zones emanate from existing heterogeneities, one would expect a correspondence between a statistical homogenization scale and the characteristic length scale of these mechanical anisotropies. We observe that the homogenization scale $\mathrm{A}_{\mathrm{RA}}$ (and with it, the scaling or growth law) increases once the largest shear zones have a length close to the width or radius of $A_{R A}$ and thereby transect the entire area of geometrical homogenization. This behavior is consistent with the notion that the effective mechanical layer thickness of the localized rock volume affects the scaling behavior [Ackermann et al., 2001]. Since the shear zones typically are oriented at angles smaller than $90^{\circ}$ (generally $30^{\circ}$ to $45^{\circ}$ ) with respect to the existing anisotropies, they can grow longer than the mechanically relevant maximum layer width (i.e., maximum shear zone length $>\mathrm{r}_{\mathrm{RAs}} / \mathrm{r}_{\mathrm{RAc}}$ ) before they crosscut this layer and the scale jump occurs. This may explain why the $\mathrm{Lf}_{\mathrm{RA}}$ length maxima are often associated with larger shear zone lengths than the maximum widths of the related existing anisotropies (Figure 8). We suggest that this observation supports our definition of $A_{R A}$.
[36] There are other reasons why peaks in the localization fraction do not always correspond with the widths of existing anisotropies and $r_{R A s} / r_{R A c}$. Some anisotropies are not relevant for localization in the entire Northern Shear Belt. For example, shear zones that are tens of meters long (Cala Cullaro, Figure 8) are longer than the widths of the largest pegmatitic bodies. These shear zones occur away from the pegmatite dikes and do not emanate from their margins. In the next section, we explore the idea that strain and the active deformation mechanisms, in addition to existing anisotropies, are also important determinates of the scales of localization.

\subsection{Effects of Strain and Kinematics}

[37] $\mathrm{D}_{\mathrm{L}}$ varies with increasing shear zone length from about 1 (quasi-linear) to 1.71 (nearly quadratic). The systematic variation of $\mathrm{Lf}_{\mathrm{RA}}$ with length was termed "multiscaling" in the Introduction. The relationship of $\mathrm{Lf}_{\mathrm{RA}}$ to width also changes with scale, but $\mathrm{D}_{\mathrm{w}}$ is more difficult to interpret (Figures 8 and 9) for two main reasons: First, measurement errors become more important and increase the data scatter; second, the width variation of the two smallest-scale data sets (Cala Prona and Rabasser metapelites) is less than half an order of magnitude, in contrast to all other data sets. This decreases the quality of the power law fit (compare correlation coefficients in Figure 9 [Bonnet et al., 2001]). Shear zones at these scales grow faster in length than in width.

[38] However, the relative values of $D_{L}$ and $D_{w}$ suggest that the aspect ratio of the shear zones first increases, then decreases with length at the largest scales (Figure 10). For millimeter- to decimeter-long shear zones, the aspect ratio 
increases from about 5 to 50. For 10-m- to kilometer-long shear zones, the aspect ratio decreases from about 80 at intermediate lengths to a minimum of 5 at the kilometer scale. This is easily confirmed by comparing the geometries of shear zones on different scales (e.g., compare trends in Figure 10 with shear zone aspect ratios in Figures $4 \mathrm{~b}$ and 5). The greater increase of the $D_{L}$ value for shear zones at the "Rabasser Quartzites" locality may reflect the different rheology of the quartz-rich rocks at this locality than of the micaceous rocks hosting the shear zones in the other localities.

[39] The evolution of the aspect ratio of shear zones with increasing length as manifested by the $D_{L}$ values for intermediate lengths belies strain-dependent changes in the dominant deformation mechanisms from brittle deformation (fracturing, cataclasis) to viscous, mylonitic shearing (dislocation and diffusion creep). These changes are in turn closely tied to a structural transition from isolated to networked shear zones, as described by Fusseis et al. [2006].

[40] At low shear strains on the grain scale, localization involves fracturing antecedent to viscous creep, as described above. This is reflected by the nearly linear scaling relationship for the shear bands at Cala Prona in Figure 8, which are thin, planar features that originated as shear fractures (Figure 5a). At centimeter to decimeter lengths (Rabasser data, Figure 8), the increasing nonlinear $\mathrm{D}_{\mathrm{L}}$ value is associated with the growing importance of viscous creep mechanisms in the center of the shear zones (dislocation creep in quartz, glide parallel to the basal [001] crystallographic plane in micas, diffusion-assisted grain boundary sliding in fine-grained qtz-fsp-mica aggregates [Fusseis, 2006]). Quartz-rich layers are asymmetrically boudinaged and rotated between mica-rich layers (Figure 6), reflecting multilayer extension [Gosh and Sengupta, 1999] during noncoaxial, mylonitic flow [Jordan, 1991]. Block rotation is associated with drag folding [Goscombe et al., 2004] adjacent to the shear bands. This is consistent with enhanced viscous creep at that scale.

[41] For shear zones ranging in length from meters to tens of meters (Figure 7), $\mathrm{D}_{\mathrm{L}}$ becomes more nonlinear (Cala Cullaró data, Figure 8) than for centimeter- to decimeterlong shear zones. Up to this crucial range of lengths, fracturing is inferred to have been active during mylonitic shearing; the fractures formed at the tips of longitudinally propagating mylonitic shear zones that are just locally interconnected [Fusseis et al., 2006]. Although some of these shear zones evidently nucleated on the same length scale as existing anisotropies (described above), many of them are clearly longer than these anisotropies (Figure 8) as they have grown longitudinally in a direction subparallel to the shearing plane. This growth explains the gap in localization data at the $10-\mathrm{m}$ scale in Figure 8. Shear zone lengthening is a more important growth mechanism than widening on the millimeter to $10-\mathrm{m}$ scales. As shown below, widening becomes more important once a threedimensional (3-D) network of shear zones is established. Increasing $\mathrm{D}_{\mathrm{L}}$ values from decimeter to meter scales are interpreted to imply that as the shear zones widen, viscous deformation mechanisms gain importance with respect to brittle deformation mechanisms. Our field measurements indicate that deformation within shear zones changes from brittle to mylonitic where displacement exceeds a critical value of about 1-2 m [Fusseis et al., 2006]. As shown in section 4.3, the mylonitic centers of these shear zones experienced softening, thus facilitating shear zone lengthening. Softening along the mylonitic centers probably results in increased displacement/strain rates leading to greater stress concentrations at the shear zone tips that in turn drive tip propagation [Cowie and Shipton, 1998].

[42] The dramatic increase in $\mathrm{D}_{\mathrm{L}}$ to nearly 2 for shear zones with lengths from hundreds to thousands of meters (Figure 8 ) is clearly related to the establishment of a network of anastomosing mylonitic shear zones (Figure $4 \mathrm{~b}$ ). At this scale, fracturing is subordinate to mylonitic deformation, such that the linkage of smaller-scale shear zones can be interpreted to coincide with a transition from brittle to viscous deformation at the crustal scale [Fusseis et al., 2006]. These anastomosing shear zones broaden with increasing strain, eventually incorporating meter- to $10-\mathrm{m}-$ sized blocks or lozenges of less deformed rock [Fusseis et al., 2006]. This lateral homogenization process is best displayed in a plot of aspect ratio versus shear zone length (Figure 10). The lozenges are inferred to have rotated during deformation, a process which is analogous to the block rotation described above, and which previous studies have shown can accommodate greater strains without lengthening the host faults [Gross et al., 1997]. Therefore both broadening of the linked shear zones and block rotation of lozenges between the shear zones may be responsible for the reduced aspect ratios of the 100-m- to kilometer-long shear zones.

[43] The change of the localization exponent, $\mathrm{D}_{\mathrm{L}}$, with increasing shear zone length primarily reflects a progressive increase in areal growth per length increment, a process which we termed network widening in the introduction. The evolution of the aspect ratios of the shear zones with length shows that lateral growth increasingly contributes to the increased areal growth (indicated by high $\mathrm{D}_{\mathrm{L}}$ values) at the largest scale. Network widening can also be regarded as delocalization (or increasing homogenization) of strain on any given scale. During purely brittle deformation in the upper crust, deformation is focused into a few, long faults that form by fault linkage within a regionally broader network of fractures [Cowie, 1998; Walsh et al., 2001]. We referred to this evolution as network narrowing above. In contrast, our examples from the Cap de Creus show that strain localization at the transition from brittle to viscous deformation results in network widening as viscous creep becomes dominant. Localization by dynamic recrystallization or diffusion-accommodated grain boundary sliding [Post, 1977; Zeuch, 1982] is an efficient mechanism to accommodate long-term loading and to weaken the deforming rock. Brittle failure occurs primarily at the tips of the propagating shear zones, where we argue that the loading rate sporadically exceeded the relaxation rate associated with viscous creep in the center of the shear zone [e.g., Fusseis et al., 2006]. Fracturing at shear zone tips predominated on the decimeter to meter scales but was subordinate on larger scales, either because the overall strain rate was lower or because fracturing was viscously damped.

[44] The linkage of shear zones coincides with a straindependent switch from cataclasis to viscous mylonitic flow on the scale of the entire Northern Shear Belt. This is because weakening in the mylonitic centers of the shear 

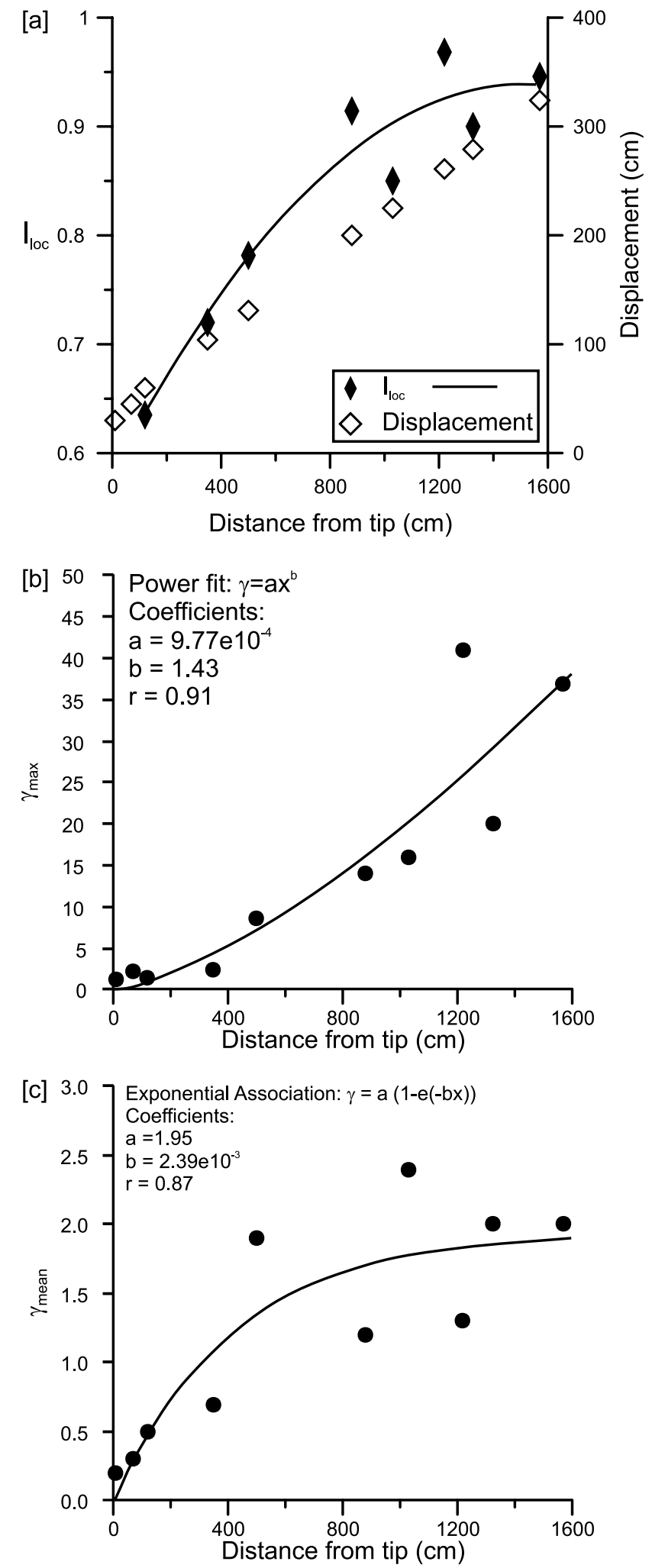

Figure 11. Plots of various measures of localization versus distance from the tip to the center of a single, meter-scale shear zone in the Cap de Creus area (Cala Prona, see Figure 4). (a) Localization intensity, $\mathrm{I}_{\mathrm{loc}}$, and displacement. (b) Maximum shear strain. (c) Mean shear strain. Distance on the horizontal axis is used as a proxy for time during shear zone evolution, increasing to the right (see text). Black lines show best fit functions to the data (discussed in text). zones drives stress buildup and propagation at the brittle shear zone tips. In the light of this, the change in $D_{L}$ values with shear zone length can be regarded as an empirical multiscaling growth law for shear zones at the brittleviscous transition.

\subsection{Do Shear Zones Soften or Harden During Network} Widening?

[45] Cataclastic and mylonitic rocks have different rheologies [e.g., Handy, 1989], but how does rheology change during network widening? Insight into this question comes from the variation of the strain localization intensity factor, $\mathrm{I}_{\mathrm{loc}}$, along and across the center of both individual and networked shear zones. Recall that $\mathrm{I}_{\mathrm{loc}}$ is a measure of the heterogeneity (i.e., the shape) of a shear strain profile across a shear zone (Figure 3). Previous workers suggested that the temporal evolution of such profiles yields insight on the changing rheology of the deformed rocks [Hull, 1988; Lamouroux et al., 1994; Means, 1995]. Inspired by Means [1984], Hull [1988] distinguished three end-member types of shear zones:

[46] 1. Type I zones harden with time. They broaden during growth and exhibit flat-topped, weakly localized strain profiles such as that shown in Figure 3a [see Hull, 1988 , Figure 4]. $\mathrm{I}_{\text {loc }}$ is small and, in an actively hardening and broadening type I shear zone, continuously decreases after an initial stage of growth related to prelocalization elastic loading and shear zone nucleation.

[47] 2. Type II shear zones either soften in their centers or harden from their boundaries to their interior. They are expected to narrow with time. The resulting finite shear strain profile becomes increasingly heterogeneous over time with a narrowing, growing central peak. $\mathrm{I}_{\mathrm{loc}}$ has rather high values and increases as long as the center of the shear zone weakens with respect to its margins.

[48] 3. Type III shear zones remain at steady state. They maintain a constant width and have a homogeneous strain distribution. This behavior is exemplified by systems undergoing homogeneous simple shear, e.g., some kink bands [Dewey, 1965]. $\mathrm{I}_{\text {loc }}$ has a constantly low value during kinking. Obviously, these end-member types of shear zones only bracket the range of possible shear zones evolutions in nature; they are conceptual vehicles for interpreting real strain profiles.

[49] Provided that spatial variations in strain are a valid proxy for time [Mitra, 1984; Means, 1995; Fusseis et al., 2006 , we can use variations of $I_{\text {loc }}$ across and along shear zones to reconstruct temporal and spatial variations in relative strength during shearing. To this end, we plotted several shear strain parameters versus the distance from the tips to the centers of a single mylonitic shear zone with appropriate markers from the Cala Prona (Figure 11, based on data from Fusseis et al. [2006]) on the premise that the displacement gradient over this distance (Figure 11a) reflects a time sequence of the shear zone evolution. That is, progressively older fabrics are preserved from the tip to the center of the shear zone. The assumption that spatial variations in structure and shear strain reflect temporal variations in the Cap de Creus shear zones is justified by structural and metamorphic evidence that shearing on the crustal scale occurred during one continuous, kinematically simple event (simple shearing) under retrograde green- 

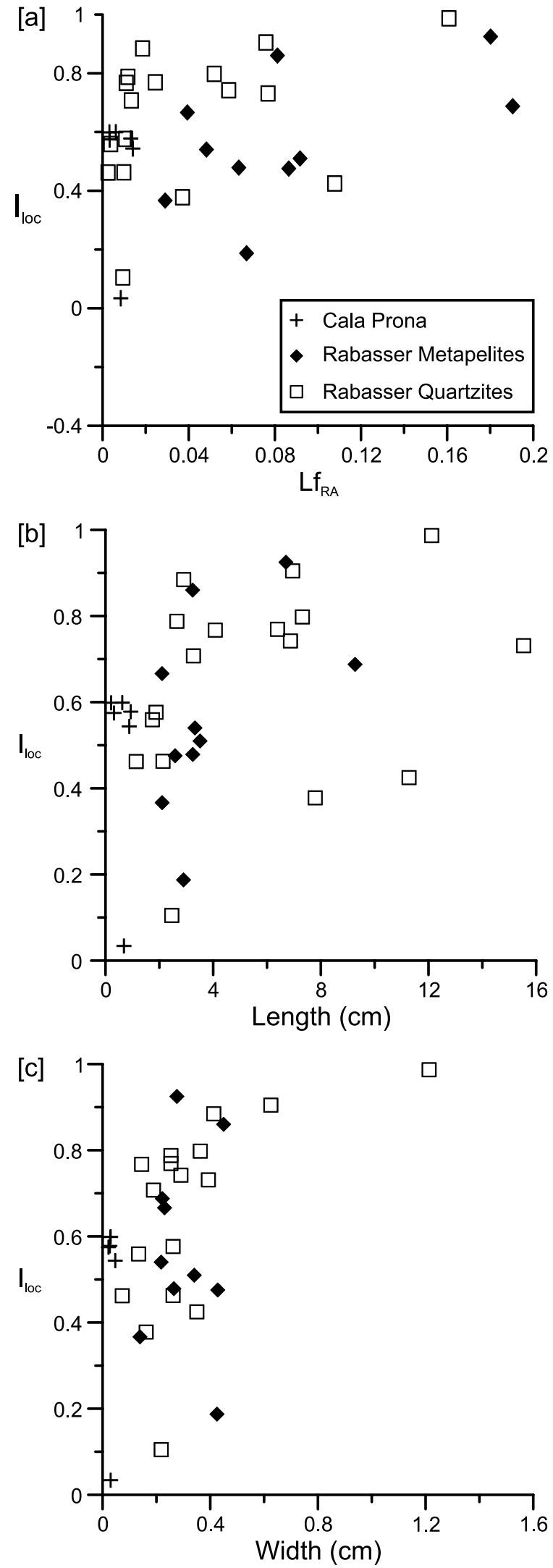

Figure 12. Plots of strain localization intensity factor, $I_{\text {loc }}$, versus (a) localization fraction, $\mathrm{Lf}_{\mathrm{RA}}$, (b) shear zone lengths, and (c) widths for the millimeter- to decimeter-long shear zones considered in this study (symbols for shear zones from different localities given in box). schist-facies conditions [Druguet, 2001; Fusseis et al., 2006]. We note that the calculated values of the strain localization intensity factor, $\mathrm{I}_{\text {loc }}$, in Figures 11 and 12, are subject to uncertainties in the determination of maximum shear strain (see Fusseis et al. [2006, appendix] for a detailed discussion). Although such estimates are fairly reliable for shear zones on length scales up to $10 \mathrm{~m}$, no markers for determining shear strain are available for the Northern Shear Belt as a whole.

[50] Displacement along the single shear zone at Cala Prona (location in Figure 4b, same as for Figure 5) increases linearly from the tip to the center of the shear zone, indicating that deformation was probably continuous on the timescale of shear zone activity [Fusseis et al., 2006]. $\mathrm{I}_{\text {loc }}$ increases with this distance as well and is best fit by a quadratic polynomial function (black line, Figure 11a). We interpret the increase in $\mathrm{I}_{\text {loc }}$ values from tip to center to reflect strain weakening of the shear zone center relative to the tips. As pointed out before [Fusseis et al., 2006], weakening can also be inferred from the evolution of maximum shear strain $\left(\gamma_{\max }\right)$ and mean shear strain $\left(\gamma_{\text {mean }}\right)$ depicted in Figures $11 \mathrm{~b}$ and 11c. The $\gamma_{\max }$ and $\gamma_{\text {mean }}$ data are best fit by power law and exponential functions, respectively (black lines in Figures $11 \mathrm{~b}$ and 11c). Because both plots refer to identical distance intervals (and hence time steps) in the same shear zone, the best fit curves indicate that the strain rate in the shear zone center accelerated with respect to the strain rate near the shear zone tips.

[51] To investigate how weakening scales with shear zone size, we plotted $I_{l o c}$ versus the localization fraction, $\mathrm{Lf}_{\mathrm{RA}}$ (Figure 12a), shear zone length (Figure 12b), and shear zone width (Figure 12c) for all millimeter- to decimeter-long shear zones presented here. The $\mathrm{I}_{\text {loc }}$ values are calculated from shear profiles where maximum displacement occurred. The smallest-scale shear zones (Cala Prona locality, Figures $4 \mathrm{~b}$ and 5) have moderate to high intensity factors and low localization fractions (Figure 12a), and their strain localization intensity factors are effectively invariant with length and width (Figures 12b and 12c). In other words, strain localization does not intensify significantly during shear band growth. Their width varies little with their length (Figure 5) so that the strain distribution within these shear bands appears rather weakly localized when regarded at the scale of a thin section. For the centimeter-scale shear zones (Rabasser Metapelites and Quartzites), $\mathrm{I}_{\text {loc }}$ correlates positively with both length and width (Figures $12 \mathrm{~b}$ and 12c), suggesting that strain localization intensifies during growth of the shear bands. We interpret this to indicate strain weakening within the shear bands, probably due to increased activity of dynamic recrystallization (structural softening of Poirier [1980]). Unfortunately, $\mathrm{I}_{\mathrm{loc}}$ could not be determined with sufficient accuracy for all larger scales.

\subsection{How Does Network Widening Work for Strain-Weakening Shear Zones?}

[52] It seems counterintuitive that shear zones like those of the Northern Shear Belt widened while the fault rocks in their centers weakened with strain. Indeed, this development contradicts the notion of Means [1984, 1995] and Hull [1988] that shear zones widen only in response to strain hardening. Yet the following arguments support the idea that a combination of rheological and geometric conditions 


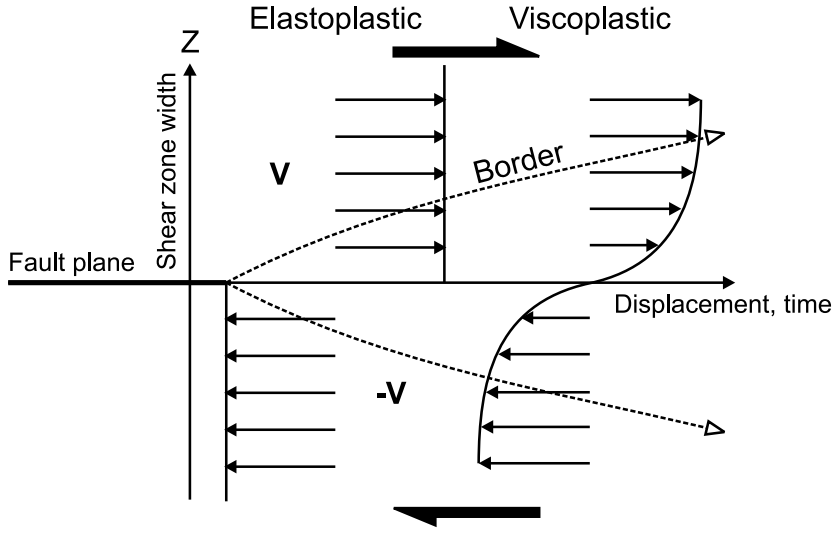

Figure 13. Shear zone widening due to a switch from elastoplastic to viscoplastic, simple shear based on the concept of a diffusing sheet vortex [after Batchelor, 2000]. The diagram shows two velocity profiles across the shear zone ( $\mathrm{Z}$ fabric direction) on the vertical axis and displacement in the transport direction (X fabric direction) on the horizontal axis. The shear zone is assumed to accommodate simple shear. Incremental velocity profiles are for a planar brittle fracture undergoing cataclasis at zero cohesion (low strain, left) and for a weaker, mylonitic shear zone deforming at constant strain rate and temperature (high strain, right). The dashed lines indicate the borders of the broadening shear zone. Initially, the brittle fault zone is a sharp discontinuity, but with the onset of viscous mylonitic flow shear forces are transmitted across the fault. A transitional layer must develop because the velocity profiles must remain continuous to ensure compatibility, thereby causing the fault zone to widen with strain.

lead to network widening during overall weakening on the crustal scale:

[53] Prior to shear zone linkage and the formation of a shear zone network, the deformation in the vicinity of an individual shear zone may be reasonably regarded as a diffusing sheet vortex between two uniform streams in free shear (Figure 13) [Batchelor, 2000]. The transition from brittle failure to thermally activated creep documented above and in previous studies [Fusseis et al., 2006] justifies regarding the continental crust as an elastoviscoplastic material; once this material yields, elastoplastic behavior at low shear strains gives way to viscoplastic rheology. Thus an initial shear fracture eventually develops a ductile, transitional layer between the two opposing streams (bounded by the diverging shear zone boundaries) to be able to accommodate the imposed simple shear (Figure 13). In other words, a narrow, almost discrete fault cannot be maintained because of the viscous drag force that develops between the undeformed rocks on either side of the displacement. The transitional layer in Figure 13 is analogous to a mylonitic shear zone with drag folds; the boundaries of this zone diverge (i.e., the shear zone widens) if the viscous material weakens, as might be expected for rocks undergoing power law creep [Evans and Kohlstedt, 1995]. However, if one assumes a constant loading rate, the shear zone will eventually attain a stable width as strain rate decreases due to widening, in turn leading to an increase in effective viscosity. We therefore believe that this mechanism of shear zone widening is restricted to isolated shear zones at the millimeter to meter scales, possibly up to the onset of shear zone networking.

[54] Once a network of mylonitic shear zones develops at scales of $100 \mathrm{~m}$ to kilometers, the widening of this network may be attributed to changes in the geometrical boundary conditions of shearing. The network of shear zones represents an interconnected weak layer or matrix that encloses lozenges of less deformed host rock [Handy, 1994]. Field evidence clearly shows that these lozenges rotated and were mylonitically overprinted as the networked shear zones grew wider [Fusseis et al., 2006]; the lozenges accommodated strains without the adjacent shear zones necessarily growing longer [Gross et al., 1997]. Consideration of the partitioning of viscous strain energy in such a network of deformed and less deformed rock suggest that networking of shear zones can weaken the continental crust by up to 10-20\% [Handy, 1994].

\section{Summary and Conclusions}

[55] Strain localization at the brittle-to-viscous transition in continental crust is strongly strain- and scale-dependent during the entire development of the shear zone network. This is illustrated in Figure 14 by a conceptual model for the evolution of the shear zones at the Cap de Creus. The model is based on a combination of the multiscaling analysis above with the time sequence of shear zone development derived previously [Carreras, 2001; Fusseis et al., 2006] from the strain gradients across the Northern Shear Belt.

[56] Localization initiated as shear fractures on one or more scales (stages a and b in Figure 14) that correspond to the three main, inherited mechanical anisotropies (grey areas in Figure 14): existing schistosity (millimeter to centimeter scales), lithological layering (decimeter to meter scales), and pegmatite bodies (meter to $10-\mathrm{m}$ scales). Two thresholds were important for the continued evolution of these shear zones in time and space:

[57] 1. The first is the attainment of a critical displacement along individual fractures facilitating viscous creep on these fractures. The onset of creep at this critical displacement weakened the shear zone centers, thereby increasing strain rate and driving fracturing and shear zone lengthening at the tips.

[58] 2. The second is the attainment of a critical shear zone length, such that the concentrated stress fields at the tips of the encroaching shear zones interacted, thereby causing these shear zones to interconnect (stage b in Figure 14). Linkage of mylonitic shear zones was associated with upward jumps in the scale of the shear zone system and is reflected by the increase in $\mathrm{D}_{\mathrm{L}}$, the power law exponent of the $\mathrm{Lf}_{\mathrm{RA}}$ length relation (stages $\mathrm{b}$ and $\mathrm{c}$ in Figure 14). Once the shear zone network reached lengths of hundreds to thousands of meters, the existing anisotropies that influenced shear zone scaling at all smaller scales (schistosity, layering, and pegmatite bodies) no longer affected shear zone scaling (stage c in Figure 14). $\mathrm{D}_{\mathrm{L}}$ reached its greatest value (almost 2) and the fully established network grew and thereby homogenized laterally. This process of "network widening" is contrary to conventional notions of strain localization, in which the deformation is considered to localize at smaller widths than the initial width(s) of initial localization. Network widening leads to the establishment of 


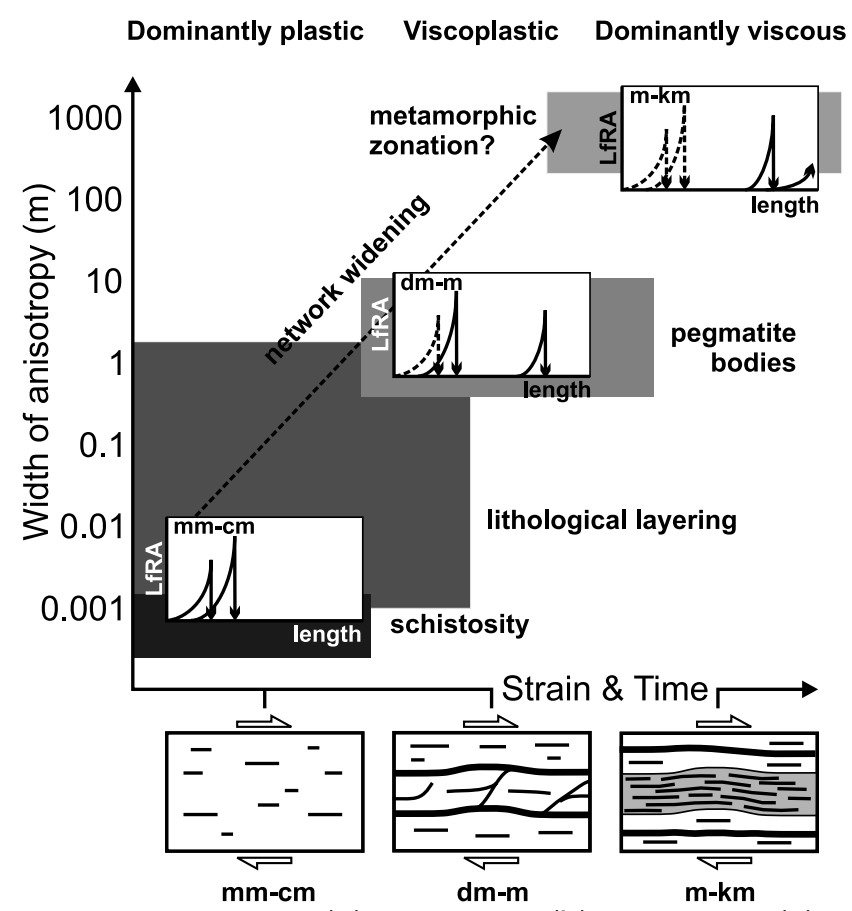

(a)

(c)
Figure 14. Conceptual model for the evolution of shear zone scale with bulk strain. The horizontal axis denotes increasing time and bulk strain. The vertical axis shows the widths of existing anisotropies in the Cap de Creus outcrops. The vertical extent of the grey rectangles corresponds to the width of the anisotropy (bold labels), whereas their horizontal extent indicates when these anisotropies affected shear zone scaling during network evolution (sketches at bottom simplified from Figure 1). The position of the schematic $\mathrm{Lf}_{\mathrm{RA}}$ length plots (stages $\mathrm{a}, \mathrm{b}$, and c) in the diagram shows how the shear zones evolved with the development of the shear zone network. $\mathrm{Lf}_{\mathrm{RA}}$ peaks in dashed lines represent length scales of the network that neither are influenced by the regarded anisotropy nor affect the scaling behavior of the system at that scale anymore. Stage a is initial fracture nucleation and propagation. Stage $b$ is attainment of critical displacement and lengths of fractures and shear zones for linkage. Stage $\mathrm{c}$ is lengthening and broadening of the shear zone network on the kilometer scale. The dominant deformation mechanisms for all networking stages are given at the top of the diagram. The scale of localization increases as the shear zones propagate and link up to form interconnected weak layers parallel to the shearing plane (see text).

a weak, mylonitic, large-scale fault system at the brittleviscous transition, which is consistent with recent fully coupled numerical models [Regenauer-Lieb et al., 2006]. In the case at hand, network widening is associated with the strain-dependent transition from brittle to viscous deformation (stage $\mathrm{c}$ in Figure 14). The increase in $\mathrm{D}_{\mathrm{L}}$ values from 1 to 2 over this broad range of length scales can therefore be regarded as an empirical, scale-variant growth law for shear zones at the continental brittle-viscous transition.

[59] Varying power law relationships have also been reported for size-frequency and displacement-length distributions on brittle faults due to strain-dependent changes of fault structure [Wojtal, 1996; Nicol et al., 1996; Gross et al., 1997], deformation mechanisms [Wojtal and Mitra, 1986, 1988; Crider and Peacock, 2004, and references therein], and effective mechanical thickness of the host rocks during fault growth [Ackermann et al., 2001]. An outstanding challenge will therefore be to compare the scaling characteristics of brittle faults and of the shear zones in our study with those of deep crustal shear zones formed well below the continental brittle-viscous transition.

\section{Appendix A}

\section{A1. Determination of $A_{R A}$, the Elementary Reference Area}

[60] Consider a foliation map with foliation traces at angles $\varphi_{\text {loc }}$ and $\varphi_{\mathrm{i}}$ to a reference line, respectively, inside and outside a shear zone (Figure 2). This foliation map is covered with a grid comprising square cells, $\mathrm{x}_{\mathrm{ai}}$ (Figures A1a and $\mathrm{A} 1 \mathrm{~b}$ ). We call this grid (and the map covered by it) a "region of interest" or ROI denotes the width of a grid cell, $\mathrm{x}_{\mathrm{a}}$, with $\mathrm{a}=2^{\mathrm{n}}$ pixel and $\mathrm{n} \in\{1,2,3, \ldots\}$ at the point $i$. Within any one of the square cells of the $\mathrm{ROI}_{\mathrm{a}}$, the mean orientation of all foliation traces, $\varphi_{\text {mi }}$, is calculated with ACFs (see below). A cell is considered to be outside of the shear zone if $\varphi_{\mathrm{mi}}$ is an element of $\varphi_{\mathrm{i}}$ (unlocalized orientations) and within the shear zone if $\varphi_{\mathrm{mi}}$ is an element of $\varphi_{\text {loc }}$ (localized orientations). The relative frequency of elements with mean orientations that are localized, Freq $\left(\varphi_{\text {loc }}\right)$, is calculated for a given $\mathrm{ROI}_{\mathrm{a}}$ and plotted versus $a$, the width of the grid cells (Figure A1c). The value of $a$ at which Freq $\left(\varphi_{\text {loc }}\right)=5 \%$ is arbitrarily designated as the length, $\mathrm{r}_{\mathrm{RAs}}$, of one side of the square representative elementary area, $A_{R A}$, such that

$$
A_{R A}=r_{R A s}^{2} .
$$

The value of $r_{\text {RAs }}$ is easily determined by interpolating linearly between points bracketing the $5 \%$ boundary on a plot of Freq $\left(\varphi_{l o c}\right)$ versus $a$ (Figure A1c).

[61] Note that this method had to be simplified for the kilometer-scale shear zones due to the lack of resolvable fabric within the shear zones on the available maps and a $\varphi_{\mathrm{i}}=\left[10^{\circ} ; 110^{\circ}\right]$. The shear zone areas were vectorized and filled with an evenly distributed, linear pattern representing the trace of the S3 mylonitic foliation parallel to the main trend of the shear zones on the map. The remaining parts of the map outside of the shear zones were filled with an evenly distributed linear pattern trending parallel to the average orientation of $\mathrm{S} 1 / 2$ at high angles to the shear zones containing S3.

\section{A2. Determining $\varphi_{\mathrm{mi}}$ With Autocorrelation Functions}

[62] This section describes how to determine the mean foliation orientation, $\varphi_{\mathrm{mi}}$, within a grid cell $\mathrm{x}_{\mathrm{ai}}$ of a region of interest. The autocorrelation function (ACF) is a statistical function that describes the spatial variability of regionalized variables. The ACF may be written

$$
\mathrm{f}(\mathrm{x}, \mathrm{y}) \otimes f(\mathrm{x}, \mathrm{y})=\int_{-\infty}^{\infty} \int_{-\infty}^{\infty} \mathrm{f}\left(\mathrm{x}^{\prime}, \mathrm{y}^{\prime}\right) \cdot \mathrm{f}\left(\mathrm{x}+\mathrm{x}^{\prime}, \mathrm{y}+\mathrm{y}^{\prime}\right) \mathrm{dx}^{\prime} \mathrm{dy}^{\prime},
$$




\section{[a]}

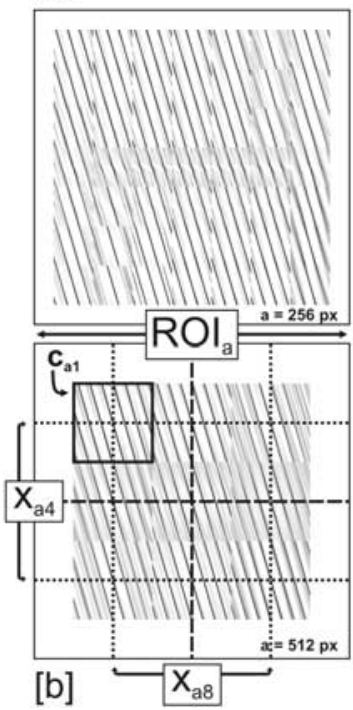

[c]

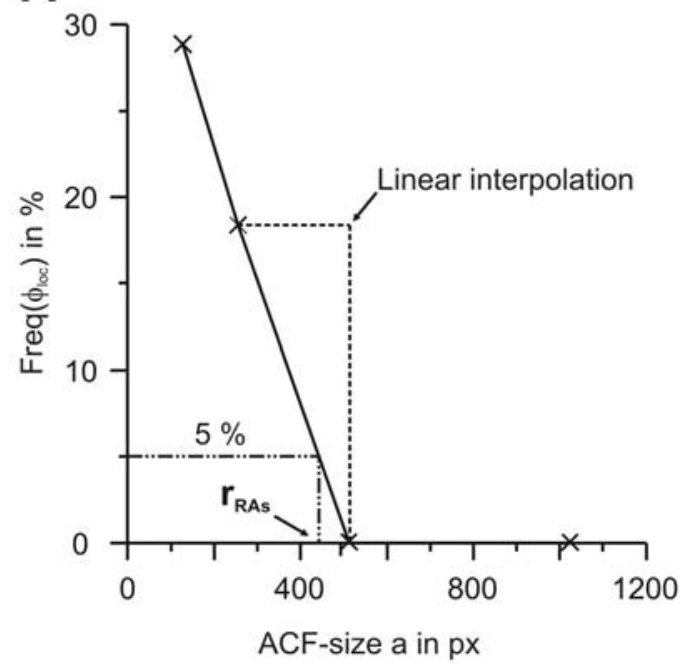

Figure A1. Determination of $\mathrm{A}_{\mathrm{RA}}$. (a) $\mathrm{ROI}_{256}$ calculated for schematic shear zone in Figure 2. Tessellated ACFs represent $\mathrm{c}_{256 \mathrm{i}}$. (b) $\mathrm{ROI}_{512}$ for same sample image as in Figure A1a showing grid cells, $\mathrm{x}_{512 \mathrm{i}}$, for which ACF centers, $\mathrm{c}_{512 \mathrm{i}}$, were calculated. The $\mathrm{x}_{\mathrm{ai}}$ overlap $1 / 2$ of their size in both horizontal and vertical directions, ensuring that the ACF center $c_{a i}$ is measured four times; this smoothes local variations of the ACF. (c) For each $\mathrm{ROI}_{\mathrm{a}}$, the proportion Freq $\left(\varphi_{\mathrm{loc}}\right)$ of $\mathrm{c}_{\mathrm{ai}}$ with $\varphi_{\mathrm{mi}} \in \varphi_{\mathrm{loc}}$ is determined and plotted versus grid cell width, $a$. $A_{R A}$ is chosen to be the square of width $\mathrm{r}_{\mathrm{RAs}}$ for which Freq $\left(\varphi_{\mathrm{loc}}\right)=$ $5 \%$. Linear interpolation between the points closest to the $5 \%$ boundary determines $\mathrm{r}_{\text {RAs }}$.

where $\mathrm{f}(\mathrm{x}, \mathrm{y})$ represents the two-dimensional brightness function defining the sample image, the operator $\otimes$ stands for a correlation or convolution, and $\mathrm{x}^{\prime}$ as well as $\mathrm{y}^{\prime}$ are the dummy variables of integration [Panozzo Heilbronner, 1992]. The value of the ACF at a given point $\left(\mathrm{x}^{\prime}, \mathrm{y}^{\prime}\right), \rho$, yields the correlation of all image points $(\mathrm{x}, \mathrm{y})$ with all neighborhood points $\left(\mathrm{x}+\mathrm{x}^{\prime}, \mathrm{y}+\mathrm{y}^{\prime}\right)$ [Panozzo Heilbronner, 1992]. The origin of the ACF coordinate system is located at the center of the ACF figure (Figure A2). The ACF figure allows one to see how well an image correlates with itself

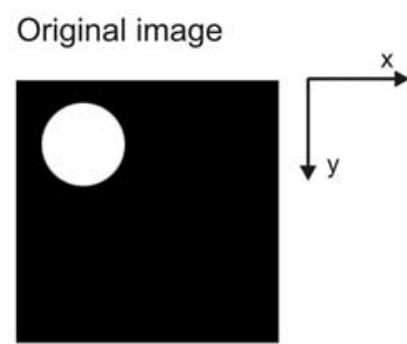

[a]

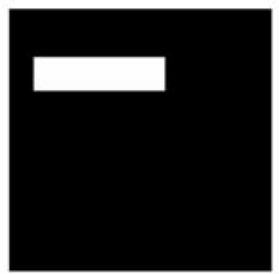

[d]
$\mathrm{ACF}$

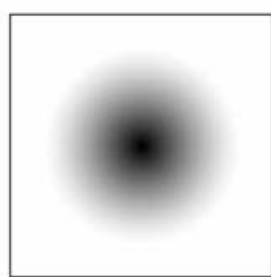

[b]

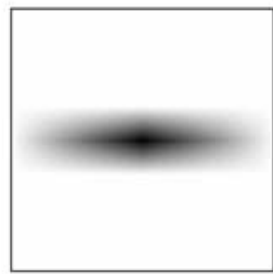

[e]

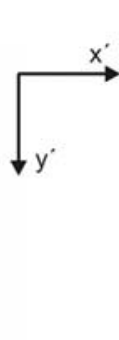

[c]
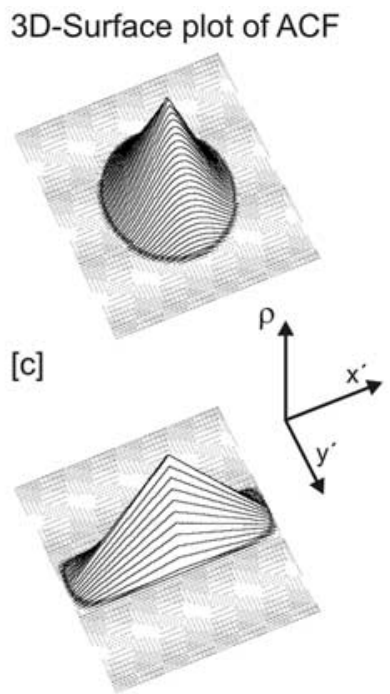

[f]

Figure A2. Visualization of the ACF [after Panozzo Heilbronner, 1992]. (a and d) Two sample images, ( $b$ and e) for which ACFs were calculated. ( $\mathrm{c}$ and f) A 3-D surface plot of the ACFs. Zero displacement is always located at the center of the ACF. Note that the gradient of the ACF brightness depends on the shape of the analyzed object. For the circle, this gradient is constant in all directions due to rotational symmetry. The ACF corresponding to the rectangle (Figure A2e) has higher gradients in the $\mathrm{y}^{\prime}$ direction because the point of zero correlation is reached more readily than in the $\mathrm{x}^{\prime}$ direction. 
when it is displaced (with respect to itself) in all possible directions [Panozzo Heilbronner, 1992]. Thus it reveals low gradients in $\rho$ parallel to elongate feature directions or to features with low spatial frequencies, and high gradients in $\rho$ parallel to short feature directions or to features with high spatial frequencies [Panozzo Heilbronner, 1992, Figure 4] (Figure A2). This property is what allows ACF figures to be used to determine directions of preferred orientation, for example, the shape-preferred orientation of platy or elongate minerals in rocks (Figure A2) [Panozzo Heilbronner, 1992; Heilbronner, 2002].

[63] In this paper, we apply ACFs to determine the mean orientation of foliation traces from 2-D images like maps and thin sections. An ACF is calculated for each constituent grid cell, $\mathrm{x}_{\mathrm{ai}}$, of a foliation map, $\mathrm{ROI}_{\mathrm{a}}$, to obtain the mean orientation of the foliation within that cell (Figures Ala and A1b). A cell typically contains several foliation traces, one or more of which may have different orientations. All of these traces determine the geometry of the ACF figure to an extent dependent on their shape, orientation and frequency. Thus the ACF averages the orientations of all objects (e.g., mica grains making up foliation) within a given cell.

[64] We used center-weighted ACFs to smooth out local aberrations in the orientation of foliation traces (Figure A1b). For any given $\mathrm{ROI}_{\mathrm{a}}$, center-weighted ACFs are calculated for each $\mathrm{x}_{\mathrm{ai}}$. The $\mathrm{x}_{\mathrm{ai}}$ overlap $1 / 2$ of their size in both horizontal and vertical directions, such that the ACF center, $c_{a i}$, is measured four times. The $\mathrm{c}_{\mathrm{ai}}$ are tessellated (Figures A1a and A1b). The orientation of the long axis of the best fit ellipsoid of the basal contour of an ACF peak in a $c_{a i}$ yields the mean orientation $\varphi_{\mathrm{mi}}$ of the related $\mathrm{x}_{\mathrm{ai}}$ [see also Panozzo Heilbronner, 1992, Figure 5c].

\section{A3. Thresholding}

[65] Thresholding is the process of separating (literally cutting off) the central ACF peak from the background noise. The shape and orientation of the central ACF peak depend on the grey value (, i.e., the correlation level, $\rho$ ) chosen to define its basal contour. This peak rises above a plane that consists of valleys and ridges (Figures A3b and A3c). For image displacements smaller than the average marker line distance, small correlations causing the valleys occur due to small overlaps of oblique or curved markers. This is unavoidable background correlation [Panozzo Heilbronner, 1992]. If the displacement is close to the average marker line distance, the overlaps increase on account of the periodicity of the foliation pattern causing ridges of higher correlation. Since only the basal contour of the central peak is of interest, the peak must be cut off not only above the background correlation level, but also such that no contacts to the adjacent ridges occur. This is necessary because the cutoff is done by binary thresholding of the grey values in the image: All values equal to or above the threshold are converted to black, whereas those below the threshold become white. If the threshold is too low, the central peak as well the major ridges are connected. As a consequence, this $c_{a i}$ contains a large, quasi-rectangular particle that does not yield the orientation of the central peak when determined automatically by a bitmap analysis software. Since the grey value distribution of the $c_{a i}$ is positively skewed (Figure A3d), we calculate the threshold simply by adding the mean grey value and its standard deviation. This yielded good results (Figure A3e). Sometimes adjacent $\mathrm{c}_{\mathrm{ai}}$ link after thresholding, resulting in their appearing to be a single particle. This bias is avoided by superposing a single-pixel, white grid of $\mathrm{c}_{\mathrm{ai}}$ mesh size.

[66] After thresholding, all remnant ridge-related particles as well as single-pixel noise are removed by a routine simply selecting the central particles and pasting them in a blank image (Figure A3f). Otherwise, the automatic image analysis routine measuring the orientations of the central particles would regard the noise as well and bias the results. The ACF data in the present paper have been calculated, processed, and evaluated using the public domain software Scion Image (http://www.scioncorp.com/) and macros by Heilbronner [2002]. For a detailed manual and the macros for denoising, please contact C. Schrank.

\section{A4. Testing the Robustness of the Method}

[67] Because the ACF figure depends on the geometry, frequency, distribution, and orientation of the marker lines in the sample image, bias must be expected due to spatial variations of these features (Figure A4). The geometrical bias is caused by variations of marker line thickness; thick marker lines reduce the average marker line distance. This results in a higher background correlation level because the overlaps due to the periodic foliation pattern occur for smaller displacements (Figure A4c). The height of the central peak compared to the basal plane decreases. Thus thresholding and denoising are rendered more difficult because the skewness of the grey value distribution is diminished. The probability of recording connected particles is increased. The proportion of $\mathrm{x}_{\mathrm{ai}}$ with $\varphi_{\mathrm{mi}}$ that are elements of $\varphi_{\mathrm{i}}$ increases as well (Figure A4d). This effect becomes more relevant for ACF sizes close to the average marker line distance. Thus huge line thickness should be avoided. On the basis of empirical considerations, we used a line thickness of one point, the horizontal image width being 1024 pixel.

[68] The frequency and distribution of marker lines depend on lithology and outcrop conditions. Gaps in marker lines due to lack of outcrop are common on maps. For foliation maps with major gaps in marker lines, the background correlation level of the ACF decreases (Figure A4a). Most segments of the marker lines outside the shear zone have a nonlocalized orientation, $\varphi_{\mathrm{i}}$. Therefore the gaps in marker lines locally reduce the periodic overlaps for displacements approximately equal to the average distance separating marker lines. The frequency of $\mathrm{x}_{\mathrm{ai}}$ with $\varphi_{\mathrm{mi}}$ being an element of $\varphi_{\mathrm{i}}$ is artificially reduced at these places. This effect increases for decreasing ACF size because the gaps become large compared to ACF size. The graph in the Freq $\left(\varphi_{\text {loc }}\right)$ versus ACF size plot is shifted upward (Figure A4d). However, the differences in the graphs decrease significantly at the scale of $r_{\text {RAs }}$ (Figure A4d).

[69] In conclusion, the divergence in the graphs reflects variations in the average marker line distance and gaps in the marker line distribution. If the size of these spatial features is small compared to the ACF size, this bias is averaged out. This is the case at the scale of $r_{R A s}$ because the average marker line distance is determined by the size of the smallest anisotropies regarded which are intrinsically small compared to $A_{R A}$ due to the geometric homogeneity condition. Nevertheless, when reasonably applicable, we 


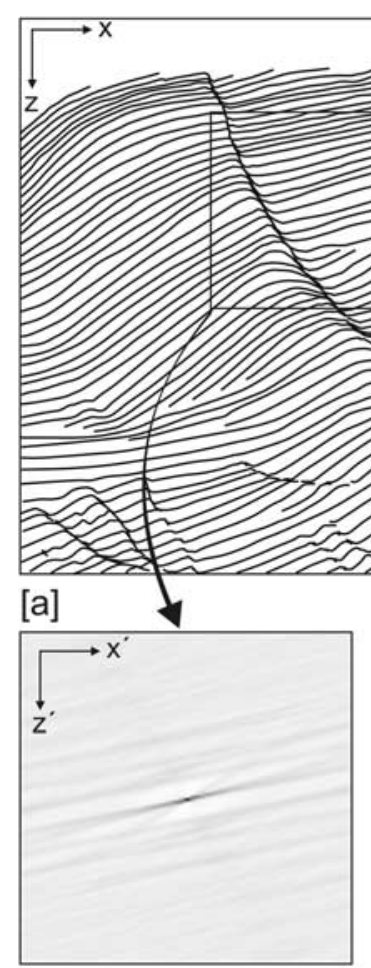

[b]

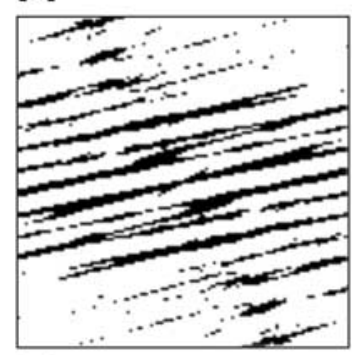

[e]

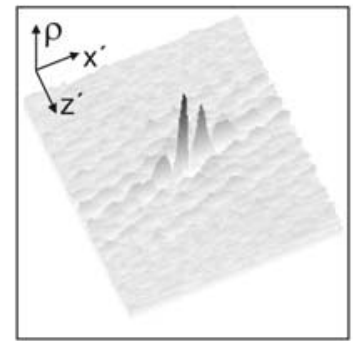

[c]

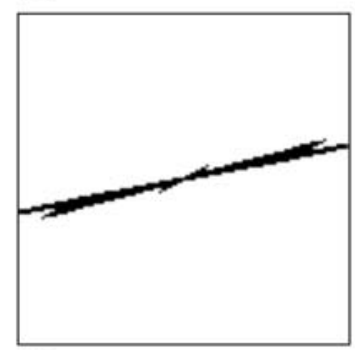

[f]

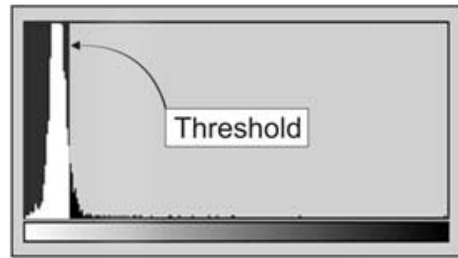

[d]

Grey values $[0 ; 255]$

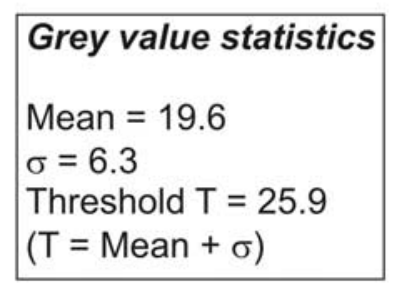

Figure A3. Thresholding and denoising of ACF centers, $\mathrm{c}_{\mathrm{ai}}$. (a) Foliation map of the Cala Cullaró area. Box with arrow marks a sample $\mathrm{x}_{\mathrm{ai}}$. Indicated $\mathrm{x}$ direction is equivalent to east in nature. (b) $\mathrm{c}_{\mathrm{ai}}$ corresponding to $x_{a i}$ indicated in Figure A3a in plane view. (c) A 3-D plot of the same $c_{a i}$. (d) Grey value distribution for depicted $c_{a i}$. (e) The parameter $c_{a i}$ after application of the proposed threshold. Note the central particle being separated from the remnant ridge particles. (f) The parameter $c_{a i}$ after thresholding and denoising. Only the basal contour of the ACF peak remains.

filled in gaps between the marker lines by interpolating their orientation and average spacing.

\section{Notation}

ACF autocorrelation function.

$\mathrm{A}_{\text {loc }}$ shear zone area in $\mathrm{XZ}$ plane of the strain ellipsoid.

$A_{R A}$ geometrically representative elementary reference area.

a length of sides of a square grid cell (search window) in a $\mathrm{ROI}_{\mathrm{a}}$.

$C_{L}$ preexponential constant of $\mathrm{Lf}_{\mathrm{RA}}$ length distribution.

$\mathrm{C}_{\mathrm{w}}$ preexponential constant of $\mathrm{Lf}_{\mathrm{RA}}$ width distribution. $c_{a i}$ ACF center calculated by a center-weighted ACF for a given $\mathrm{ROI}_{\mathrm{a}}$ at the grid cell $\mathrm{x}_{\mathrm{ai}}$.

$\mathrm{d}$ displacement at a given shear zone section.

$D_{L}$ power law exponent of $L f_{R A}$ length distribution.

$\mathrm{D}_{\mathrm{w}}$ power law exponent of $\mathrm{Lf}_{\mathrm{RA}}$ width distribution. Freq $\left(\varphi_{\text {loc }}\right)$ frequency distribution of cells with orientation $\varphi_{\text {loc }}$ for a given $\mathrm{ROI}_{\mathrm{a}}$.

$I_{\text {loc }}$ strain localization intensity.

$\mathrm{L}$ shear zone length in $\mathrm{XZ}$ section of the strain ellipsoid.

$\mathrm{Lf}_{\mathrm{RA}}$ localization fraction, normalized shear zone area.

$r_{R A s}$ length of the sides of the square of area $A_{R A}$.

$r_{R A c}$ diameter of the circle of area $A_{R A}$.

REV representative elementary volume. 

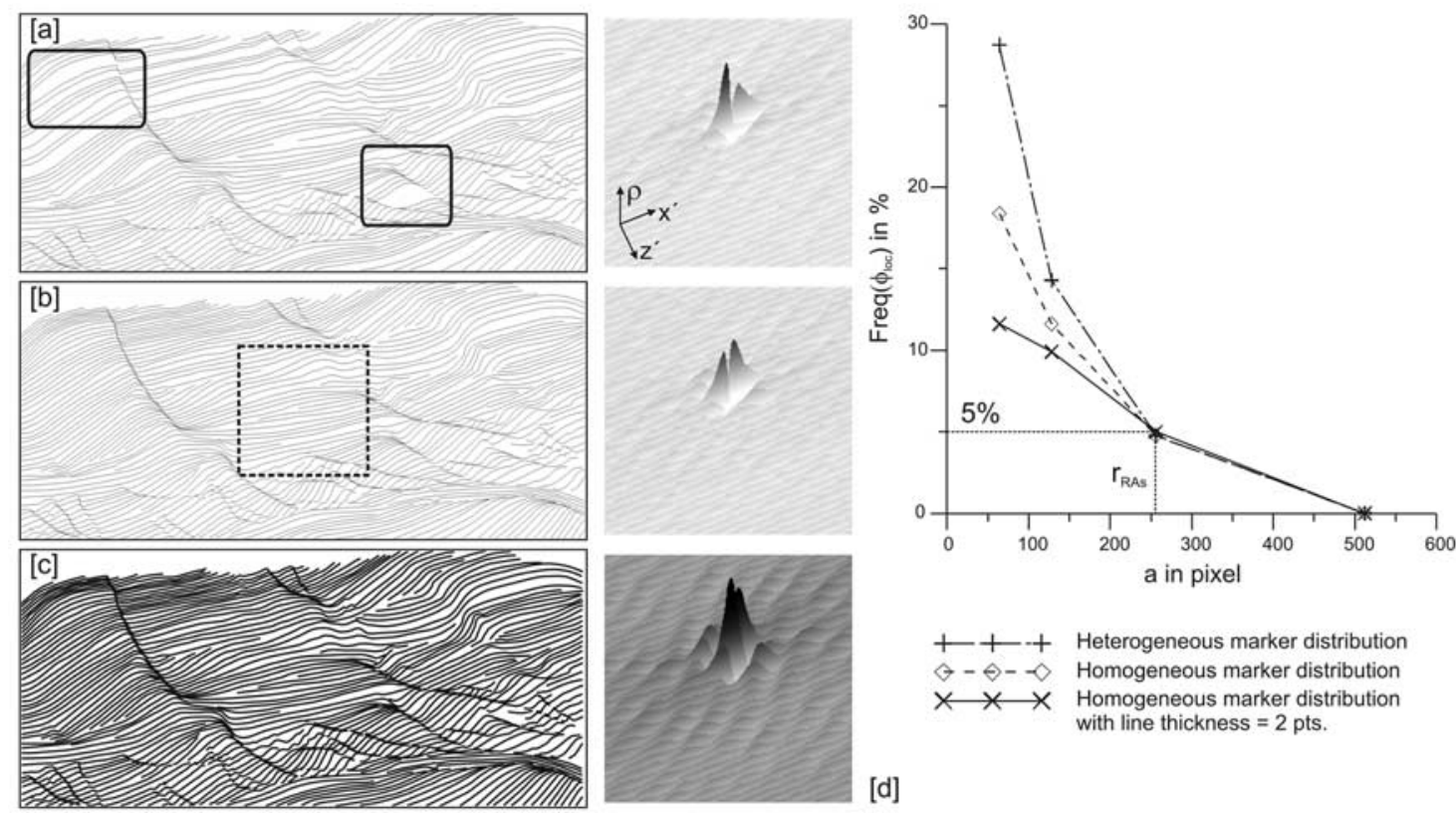

$x \times \times$ Homogeneous marker distribution with line thickness $=2$ pts.

[d]

Figure A4. Influence of marker line distribution and line thickness on $A_{R A}$. Three versions of a foliation map are shown including close-up view of the related ACF peak calculated for the central image area (Figures A4a-A4c) (dashed square in Figure A4b shows location of $\mathrm{x}_{\mathrm{ai}}$ ). Note that the horizontal axes of the ACF plots have the same scale, whereas the vertical axes are scaled differently. The peak maximum is always at the same height (matching a correlation level of unity). (a) Heterogeneous foliation map with line thickness of 1 point, exposing major gaps in line distribution (examples marked by rounded squares). (b) Homogenized foliation map of line thickness of 1 point. (c) Homogenized foliation map with line thickness of 2 points. (d) Plot of Freq $\left(\varphi_{\text {loc }}\right)$ versus ACF size for all sample images.

$\mathrm{ROI}_{\mathrm{a}}$ region of interest, grid covering a foliation map with square grid cells of width $a$.

W transversal shear zone width at a given section.

$\mathrm{x}_{\mathrm{ai}}$ single square grid cell of a given $\mathrm{ROI}_{\mathrm{a}}$ at the place i.

$\gamma$ shear strain.

$\gamma_{\max }$ maximum shear strain in a transversal shear strain profile of a shear zone.

$\gamma_{\text {mean }}$ mean shear strain of a transversal shear strain profile across a shear zone.

$\varphi_{\mathrm{i}}$ initial, undeformed orientation interval of marker lines.

$\varphi_{\text {loc }}$ deformed, localized orientation interval of marker lines.

$\varphi_{\mathrm{mi}}$ mean orientation of $\mathrm{a}_{\mathrm{ai}}$ calculated by ACF.

$\varphi_{\mathrm{p}}$ orientation of the tangent in a point $\mathrm{P}$ on a marker line of a foliation map.

$\rho$ level of correlation yielded by ACF for a given displacement $\left(\mathrm{x}+\mathrm{x}^{\prime}, \mathrm{y}+\mathrm{y}^{\prime}\right)$.

[70] Acknowledgments. We thank Jordi Carreras and Elena Druguet for fruitful discussions on the Cap de Creus shear zones and assistance in dealing with Catalan authorities. Roland Christmann's excellent map of the Cala Cullaro was the basis for the analysis of decameter-scale shear zones. David Boutelier is thanked for inspiring discussions. We also thank Bob Holdsworth and Timothy Little for their thorough and very helpful reviews, although we hasten to add that they did not agree with all of our conclusions; we alone are responsible for this paper's contents. This paper is based on the results of the first author's Diploma thesis and the third author's Ph.D., both conducted at the Freie Universität Berlin (FUB) in 2002-2005. Our work was supported by the German Science Foundation
(DFG) in the form of grant Ha 2403/6 and by the FUB with a tutorial stipend and postgraduate assistantship, respectively, to C.S. and F.F.

\section{References}

Ackermann, R. V., R. W. Schlische, and M. O. Withjack (2001), The geometric and statistical evolution of normal fault systems: An experimental study of the effect of mechanical layer thickness on scaling laws, J. Struct. Geol., 23(11), 1803-1819.

Alfonso, P., J. C. Melgarejo, I. Yusta, and F. Velasco (2003), Geochemistry of feldspars and muscovite in granitic pegmatite from the Cap de Creus field, Catalonia, Spain, Can. Mineral., 41, 103-116.

Batchelor, G. K. (2000), An Introduction to Fluid Dynamics, First Cambridge Mathematical Library Edition, Univ. of Cambridge Press, New York.

Bauer, P., S. Palm, and M. R. Handy (2000a), Strain localization and fluid pathways in mylonite: Inferences from in situ deformation of a waterbearing quartz analogue (norcamphor), Tectonophysics, 320, 141-165.

Bauer, P., M. R. Handy, and C. Rosenberg (2000b), 'See-through' deformation experiments on brittle-viscous norcamphor at controlled temperature, strain rate and applied confining pressure, J. Struct. Geol., 22, 281-289.

Ben-Zion, Y., and C. G. Sammis (2003), Characterization of fault zones, Pure Appl. Geophys., 160, 677-715.

Biot, M. A. (1964), Theory of internal buckling of a confined multilayered structure, Geol. Soc. Am. Bull., 75, 563-568.

Bonnet, E., O. Bour, N. E. Odling, P. Davy, I. Main, P. Cowie, and B. Berkowitz (2001), Scaling of fracture systems in geological media, Rev. Geophys., 39, 347-383.

Bons, P. D., E. Druguet, I. Hamann, J. Carreras, and C. W. Passchier (2004), Apparent boudinage in dykes, J. Struct. Geol., 26, 625-636.

Carreras, J. (2001), Zooming on northern Cap de Creus shear zones, J. Struct. Geol., 23, 1457-1486.

Carreras, J., and E. Druguet (1994), Structural zonation as a result of inhomogeneous non-coaxial deformation and its control on syntectonic intrusions: An example from the Cap de Creus area, eastern-Pyrenees, J. Struct. Geol., 16, 1525-1534. 
Carter, N. L., and M. C. Tsenn (1987), Flow properties of the continental lithosphere, Tectonophysics, 136, 27-63.

Cobbold, P. R., J. W. Cosgrove, and M. Summers (1971), The development of internal structures in deformed anisotropic rocks, Tectonophysics, 12, $23-53$.

Cosgrove, J. W. (1989), Cleavage, folding and the finite strain ellipsoid, Proc. Geol. Assoc., 100, 461-479.

Cosgrove, J. W. (1997), The influence of mechanical anisotropy on the behavior of the lower crust, Tectonophysics, 280, 1-14.

Coward, M. P. (1976), Strain within ductile shear zones, Tectonophysics, $34,181-197$

Cowie, P. A. (1998), A healing-reloading feedback control on the growth rate of seismogenic faults, J. Struct. Geol., 20, 1075-1087.

Cowie, P. A., and C. H. Scholz (1992), Displacement-length scaling relationship for faults: Data synthesis and discussion, J. Struct. Geol., 14, $1149-1156$.

Cowie, P. A., and Z. K. Shipton (1998), Fault tip displacement gradients and process zone dimensions, J. Struct. Geol., 20, 983-997.

Crider, J. G., and D. C. P. Peacock (2004), Initiation of brittle faults in the upper crust: A review of field observations, J. Struct. Geol., 26, $691-707$

Dewey, J. F. (1965), Nature and origin of kink-bands, Tectonophysics, 1 , 459-494.

Druguet, E. (2001), Development of high thermal gradients by coeval transpression and magmatism during the Variscan orogeny: Insights from the Cap de Creus (eastern Pyrenees), Tectonophysics, 332, 275-293.

Druguet, E., and D. H. W. Hutton (1998), Syntectonic anatexis and magmatism in a mid-crustal transpressional shear zone: An example from the Hercynian rocks of the eastern Pyrenees, J. Struct. Geol., 20, 905-916.

Druguet, E., C. W. Passchier, J. Carreras, P. Victor, and S. den Brok (1997), Analysis of a complex high-strain zone at Cap de Creus, Spain, Tectonophysics, 280, 31-45.

Dutruge, G., J.-P. Burg, J. Lapierre, and J.-L. Vigneresse (1995), Shear strain analysis and periodicity within shear gradients of metagranite shear zones, J. Struct. Geol., 17, 819-830.

Evans, B., and D. L. Kohlstedt (1995), Rheology of Rocks, in Rock Physics and Phase Relations: A Handbook of Physical Constants, Ref. Shelf, vol 3, edited by T. J. Ahrens, pp. 148-165, AGU, Washington, D. C.

Fusseis, F. (2006), Strain localization and shear zone formation at the brittle-viscous transition, Cap de Creus, Spain, Ph.D. thesis, 195 pp., Free Univ. Berlin, Berlin, Germany, 19 Dec.

Fusseis, F., and M. R. Handy (2006), Grain-scale processes and inferred stress drops during the formation of shear zone networks at the brittle-toviscous transition (BVT), Geophys. Res. Abstr., 8, 07323.

Fusseis, F., M. R. Handy, and C. E. Schrank (2006), Networking of shear zones at the brittle-to-viscous transition (Cap de Creus, NE Spain), J. Struct. Geol., 28, 1228-1243.

Goscombe, B. D., C. W. Passchier, and M. Hand (2004), Boudinage classification: End-member boudin types and modified boudin structures, J. Struct. Geol., 26, 739-763.

Gosh, S. K., and S. Sengupta (1999), Boudinage and composite boudinage in superimposed deformations and syntectonic migmatization, J. Struct. Geol., 21, 97-110.

Gottschalk, R., A. K. Kronenberg, J. E. Russell, and J. Handin (1990), Mechanical anisotropy of Gneiss: Failure criterion and textural sources of directional behavior, J. Geophys. Res., 95, 21,613-21,634.

Gross, M. R., G. Gutiérrez-Alonso, T. Bai, M. A. Wacker, and K. B. Collinsworth (1997), Influence of mechanical stratigraphy and kinematics on fault scaling relations, J. Struct. Geol., 19, 171-183.

Handy, M. R. (1989), Deformation regimes and the rheological evolution of fault zones in the lithosphere: The effects of pressure, temperature, grain size and time, Tectonophysics, 163, 119-152.

Handy, M. R. (1994), The energetics of steady state heterogeneous shear in mylonitic rock, Mater. Sci. Eng., A175, 261-272.

Handy, M. R., and J.-P. Brun (2004), Seismicity, structure and strength of the continental lithosphere, Earth Planet. Sci. Lett., 223, 427-441.

Handy, M. R., G. Hirth, and R. Bürgmann (2007), Continental fault structure and rheology from the frictional-viscous transition downward, in Tectonic faults - Agents of Change on a Dynamic Earth, edited by M. R. Handy, G. Hirth, and N. Hovius, pp. 139-182, MIT Press, Cambridge, Mass.

Heilbronner, R. (2002), Analysis of bulk fabrics and microstructure variations using tessellation of autocorrelation functions, Comput. Geosci., 28 , $447-455$.

Heim, A. (1878), Untersuchungen über den Mechanismus der Gebirgsbildung im Anschluss an die geologische Monographie der TödiWindgällen-Gruppe, 3 vols., Benno Schwabe, Basel, Switzerland.
Herwegh, M., and M. R. Handy (1996), The evolution of high-temperature mylonitic microfabrics: Evidence from simple shearing of a quartz analogue (norcamphor), J. Struct. Geol., 18, 689-710.

Herwegh, M., and M. R. Handy (1998), The origin of shape preferred orientations in mylonite: Inference from in-situ experiments of polycrystalline norcamphor, J. Struct. Geol., 20, 681-694.

Hippertt, J. (1999), Are S-C structures, duplexes and conjugate shear zones different manifestations of the same scale-invariant phenomenon?, J. Struct. Geol., 21, 975-984

Holyoke, C. W., and J. Tullis (2006), Formation and maintenance of shear zones, Geology, 34, 105-108.

Hull, J. (1988), Thickness-displacement relationships for deformation zones, J. Struct. Geol., 10, 431-435.

Jordan, P. G. (1991), Development of asymmetric shale pull-aparts in evaporite shear zones, J. Struct. Geol., 13, 399-409.

Lai, W. M., D. Rubin, and E. Krempl (1996), Introduction to Continuum Mechanics, 3rd ed., Elsevier, New York.

Lamouroux, C., P. Debat, J. Inglès, N. Guerrero, P. Sirieys, and J. C. Soula (1994), Rheological properties of rock inferred from the geometry and microstructure in two natural shear zones, Mech. Mater, 18, 79-87.

Lei, X., K. Kusunose, T. Satoh, and O. Nishizawa (2003), The hierarchical rupture process of a fault: An experimental study, Phys. Earth Planet Inter., 137, 213-228.

Lloyd, G. E., and R. J. Knipe (1992), Deformation mechanisms accommodating faulting of quartzite under upper crustal conditions, J. Struct. Geol., 14, 127-143.

Mainprice, D., J. Bascou, P. Cordier, and A. Tommasi (2004), Crystal preferred orientations of garnet: Comparison between numerical simulations and electron-backscattered diffraction (EBSD) measurements in naturally deformed eclogites, J. Struct. Geol., 26, 2089-2102.

Mandelbrot, B. B. (1982), The Fractal Geometry of Nature, W. H. Freeman, New York.

Means, W. D. (1976), Stress and Strain, Basic Concepts of Continuum Mechanics for Geologists, 339 pp, Springer, New York.

Means, W. D. (1984), Shear zones of types I and II and their significance for reconstruction of rock history, Geol. Soc. Am. Abstr. Programs, 16, 50 .

Means, W. D. (1995), Shear zones and rock history, Tectonophysics, 247, $157-160$.

Milnes, A. G. (1979), Albert Heim's general theory of natural rock deformation (1878), Geology, 7, 99-103.

Mitra, G. (1984), Brittle to ductile transition due to large strains along the White Rock thrust, Wind River mountains, Wyoming, J. Struct. Geol., 6, $51-61$.

Nicol, A., J. J. Walsh, J. Watterson, and P. A. Gillespie (1996), Fault size distributions-are they really power-law?, J. Struct. Geol., 18, 191-197.

Panozzo Heilbronner, R. (1992), The autocorrelation function: An image processing tool for fabric analysis, Tectonophysics, 212, 351-370.

Paterson, M. S. (2001), Relating experimental and geological rheology, Int. J. Earth Sci., 90, 157-167.

Poirier, J. P. (1980), Shear localization and shear instability in materials in the ductile field, J. Struct. Geol., 2, 135-142.

Post, R. L. (1977), High-temperature creep of Mt. Burnet Dunite, Tectonophysics, 42, 75-110.

Ramberg, H. (1955), Natural and experimental boudinage and pinch-andswell structures, J. Geol., 63, 512-526.

Ramsay, J. G. (1980), Shear zone geometry: A review, J. Struct. Geol., 2, 83-99.

Ramsay, J. G., and R. H. Graham (1970), Strain variation in shear belts, Can. J. Earth Sci., 7, 786-813.

Regenauer-Lieb, K., R. F. Weinberg, and G. Rosenbaum (2006), The effect of energy feedbacks on continental strength, Nature, 442, 67-70, doi:10.1038/nature04868.

Robinson, D. K., and P. R. Bevington (2003), Data Reduction and Error Analysis for the Physical Sciences, 3rd ed., 320 pp., McGraw-Hill, Boston, Mass.

Schrank, C. E. (2004), Quantification of strain localization in ductile shear zones, Diploma thesis, 62 pp., Freie Univ., Berlin, Germany.

Shea, W. T., and A. K. Kronenberg (1993), Strength and anisotropy of foliated rocks with varied mica content, J. Struct. Geol., 15, 1097-1121. Simpson, C. (1983), Displacement and strain patterns from naturally occurring shear zone terminations, J. Struct. Geol., 5, 497-506.

Tchalenko, J. S. (1970), Similarities between shear zones of different magnitudes, Geol. Soc. Am. Bull., 81, 1625-1640.

Turcotte, D. L. (1990), Implications of chaos, scale-invariance, and fractal statistics in geology, Palaeogeogr. Palaeoclimatol. Palaeoecol., 89 , $301-308$ 
Walsh, J. J., et al. (2001), Geometric controls on the evolution of normal fault systems, in The Nature and Tectonic Significance of Fault Zone Weakening, edited by R. E. Holdsworth et al., Geol. Soc. Spec. Publ., $186,157-170$.

White, S. H., S. E. Burrows, J. Carreras, N. D. Shaw, and F. J. Humphreys (1980), On mylonites in ductile shear zones, J. Struct. Geol., 2, 175-187.

Wojtal, S. F. (1996), Changes in fault displacement populations correlated to linkage between faults, J. Struct. Geol., 18, 265-279.

Wojtal, S., and G. Mitra (1986), Strain hardening and strain softening in fault zones from foreland thrusts, Geol. Soc. Am. Bull., 97, 674-687.

Wojtal, S., and G. Mitra (1988), Nature of deformation in fault rocks from Appalachian thrusts, in Geometries and Mechanisms of Thrusting, With Special Reference to the Appalachians, edited by G. Mitra and S. Wojtal, Spec. Pap. Geol. Soc. Am., 222, 17-33.
Zeuch, D. H. (1982), Ductile faulting, dynamic recrystallization and grainsize sensitive flow of olivine, Tectonophysics, 83, 293-308.

F. Fusseis, School of Earth and Geographical Sciences (m004), University of Western Australia, Stirling Highway, Perth 6009, WA, Australia.

M. R. Handy, Institut für Geologische Wissenschaften, Fachrichtung Geologie, Malteserstrasse 74-100, Haus B, D-12249 Berlin, Germany.

C. E. Schrank, Department of Geology, University of Toronto, 22 Russell Street, Toronto, ON, Canada M5S 3B1. (schrank@geology.utoronto.ca) 